Article

\title{
Inclusions in and Exclusions from the S\&P 500 Environmental and Socially Responsible Index: A Fuzzy-Set Qualitative Comparative Analysis
}

\author{
Juan Pineiro-Chousa ${ }^{1, *}$, Noelia Romero-Castro ${ }^{1}$ (D) and Marcos Vizcaíno-González ${ }^{2}$ (D) \\ 1 Department of Financial Economics and Accounting, Universidade de Santiago de Compostela, \\ Santiago de Compostela 15782, Spain; noe.romero@usc.es \\ 2 Department of Business, Universidade da Coruña, A Coruña 15071, Spain; marcos.vizcaino@udc.es \\ * Correspondence: j.pineiro@usc.es; Tel.: +34-982824466
}

Received: 28 December 2018; Accepted: 19 February 2019; Published: 25 February 2019

check for updates

\begin{abstract}
Socially responsible investment (SRI) indices provide an interesting opportunity to analyse the links between corporate financial performance (CFP) and corporate sustainability performance (CSP). However, few studies focus on the antecedents of inclusions in and exclusions from SRI indices. Specifically, the implications of corporate sustainability disclosure (CSD) have been largely ignored in this field. Furthermore, previous literature on the CSP-CSD-CFP links shows inconclusive results that have been attributed to both methodological and measurement problems, which suggest the existence of asymmetry, equifinality and complexity amongst these links. This study targets two under-researched areas regarding the determinants of changes in the composition of SRI indices, and the effects of CSD on CSP. This study also attempts to overcome the methodological and measurement limitations of previous studies on the CFP-CSD-CSP links. The study presents a fuzzy-set qualitative comparative analysis (fsQCA) to explore how different combinations of CFP and CSD indicators are related to inclusions in an SRI index (assumed as expressions of a good CSP), and exclusions from an SRI index (equivalent to a poor CSP). The empirical results reveal that a combination of different CSD indicators is necessary, but not sufficient, to lead to the inclusion in or exclusion from an SRI index, and that CFP measures have asymmetrical effects on CSP. CSD is a relevant antecedent or precondition of CSP that can motivate changes in corporate behaviours towards an improved CSP. Poor CSP, leading to an exclusion from the index, is associated with poor CSD and a deterioration of CFP. The implications for researchers, business managers, SRI rating agencies and policymakers are derived.
\end{abstract}

Keywords: SRI indices; corporate sustainability performance; corporate sustainability disclosure; corporate financial performance; equifinality; asymmetry; complexity; fsQCA

\section{Introduction}

The relationship between corporate financial performance (CFP) and corporate sustainability performance (CSP) is probably one of the most researched subjects in the field of corporate sustainability [1]. The terms corporate sustainability, corporate social responsibility (CSR) or environmental, social and governance (ESG) are used interchangeably both among practitioners and researchers [1]. Two prominent strands within this vast academic literature are those focused on (1) the analysis of socially responsible investment (SRI) strategies in general, and sustainability stock indices in particular, and (2) on the analysis of the relevance and impact of the disclosure of sustainability information in the form of sustainability reports [2]. These two topics are greatly interrelated because corporate sustainability disclosure (CSD) is the basis for the development of SRI in general and for the construction of sustainability stock indices in particular. 
Sustainability, or SRI indices have been mainly used under this CSP-CFP field of research in three ways: (1) As a proxy for CSP, taking into consideration that being listed into a sustainability index is synonymous of having a good CSP [3]; (2) to conduct event studies analysing whether the announcement of the inclusion and exclusion events has any significant impact on stock returns [4-6]; and (3) to analyse the financial performance of sustainability indices, funds or portfolios against the performance of conventional or non-sustainability-screened ones (see [7] for a meta-analysis of previous research on this topic). Although their contributions are highly relevant, the implications of entering or dropping out of a sustainability index have been object of analysis in a small number of papers compared to other approaches to exploring the relationship between CFP and CSP [6].

This study approaches the analysis of the CSP-CFP link in a rather particular fashion, by combining the first two strands of this literature based on SRI indices: On one hand, being listed or delisted from an SRI index are considered proxies for a good and poor CSP, respectively; and on the other hand, we focus on inclusion and exclusion events, but instead of trying to explain their impact on CFP, we explore whether inclusions and exclusions, as expressions or result of a good or poor CSP, are related to, or explained by, CSD and CFP.

As most sustainability indices are designed and managed to comprise companies with a superior or outstanding CSP, it can be assumed that entering a sustainability index is equivalent to displaying a good CSP and that the exclusion from a sustainability index means a worsening of CSP. This assertion is far from universally accepted and the role of rating agencies behind SRI indices has been criticised. The processes and methods for the assessment of the sustainability commitment and performance of companies, do not clearly specify the reasons behind the high or low sustainability scores of a company, and the diversity of ratings and methodologies only adds to the confusion and distrust $[8,9]$. Furthermore, inclusions in SRI indices have been associated with factors other than CSP [10]. Nevertheless, given that the meaning of SRI indices is to help investors assessing CSP, it seems logical to assume that they represent CSP, even though they do not measure it directly [11].

The disclosure of sustainability information and the quality of that information are essential factors in the construction of sustainability stock indices, because third-party rating agencies gather this information both through their own questionnaires and from publicly accessible sources [9] such as sustainability reports. Nevertheless, the influence of CSD on CSP has been under-explored by previous literature. This study aims at addressing that research gap. Companies with a high commitment to CSD can be assumed to have also a good CSP $[12,13]$ and, consequently, a high probability of being included in a sustainability index. Therefore, we argue that a good CSD is a necessary condition to show a good CSP, which leads to the company's inclusion in a SRI index, and that a poor CSD can explain a poor CSP, which leads to an exclusion from a SRI index.

CFP is also an essential condition for the inclusion in or exclusion from any stock index, and hence for sustainability-focused ones. Although previous research has mainly focused on the impacts of CSP on CFP [14], the reverse causality has also been explicitly analysed [15]. We also target this less developed strand of research by focusing on the influence of CFP on CSP and arguing that firms with superior CFP can be included in a sustainability index because a superior CFP enables a good CSP, which results in being listed or maintained in the index. Furthermore, a superior CFP, regardless of being linked to a superior CSP, can be valued by the stock market. A situation like that would result in a higher stock price and an increased market capitalization, which facilitates the company's inclusion in SRI indices because market capitalization is usually considered an important factor. Therefore, considering both accounting and market-based measures of CFP seems obliged in this context, as accounting measures can indicate the availability of financial resources for an improved CSP, while market measures can capture long-term expectations regarding CSP and thus directly influence inclusions in or exclusions from a SRI index.

Previous research has dealt with all possible hypotheses regarding the relationship among CFP, CSD and CSP. The three variables have been used as independent and dependent variables in different studies, but the results are inconclusive [14]. This situation has raised demands for more research 
in order to reduce variability in theory and results and facilitate convergence. This study adopts an exploratory approach and assumes (1) that complex interactions exist among the variables, (2) that there are several alternatives to achieve the same outcome and (3) that the same cause can produce different outcomes. These premises imply the application of a configurational approach to analyse the sufficient and necessary causes of an outcome [16]. Qualitative Comparative Analysis (QCA), which, to our knowledge, has only been incipiently applied in the analysis of the CFP and CSP relationship [17], provides a suitable methodological framework in this context.

Sustainability indices are actively managed by their corresponding providers; therefore, at each index revision, companies listed in the index can be removed, and new companies can be added. Interestingly, some companies experience successive inclusions and exclusions from the same index throughout their life span. These cases seem particularly attractive to explore due to the reasons behind this variability. While previous research related to sustainability indices has mainly focused on analysing the implications of just being listed in a sustainability index, or of being included in or excluded from an index as separate events, this study analyses the interrelations between the events of being included in and excluded from an index. In particular, we are interested in the analysis of the exclusion from a sustainability index following an inclusion taking place after the initial index configuration, and the inclusion following a previous exclusion.

Thus, our research objectives are two-fold and aim at filling current research gaps. First, we explore two issues that seem to have been largely neglected in previous literature, identifying the factors that explain inclusions in or exclusions from SRI indices. Specifically, the analysis addresses the influence of CSD on CSP, with a singular focus on the companies that appear to have a rather volatile CSP, leading to subsequent inclusions in or exclusions from an SRI index. Second, the study contributes to the incipient application of the QCA framework to the analysis of the complex and asymmetrical CSP-CSD-CFP links in order to shed a new light on the conflicting perspectives and inconclusive findings of prior research.

This study moves away from traditional statistical techniques, and relies on the fuzzy-set Qualitative Comparative Analysis (fsQCA) technique to assess the causal complexity among the concepts of CSD, CFP and CSP. More concretely, this study analyses the necessity and sufficiency of different CSD and CFP causal conditions regarding companies' CSP measured through the inclusion in or exclusion from an SRI index. The sample comprises 126 exclusions from and inclusions in the S\&P 500 Environmental and Socially Responsible Index, experienced by 99 S\&P 500 companies over the period 2010-2016. The results obtained show complex interrelations among causal conditions, some of which can contribute to both good and poor CSP (inclusion in or exclusion from an SRI index). Furthermore, the analysis identifies different paths or combinations of causal conditions that are sufficient but not necessary for a good or poor CSP. The results also provide evidence that there is no single necessary causal condition for a specific outcome, and that combinations of causal conditions associated with a good CSP (index inclusion) are not the mirror opposite of those associated with a poor CSP (index exclusion). In particular, we conclude that companies included in the index after a previous exclusion show a comparatively higher commitment to CSD, whereas companies excluded after a previous inclusion show a lower or no commitment to CSD. Regarding the CFP-CSP link, results reflect an ambiguous role of alternative CFP measures in relation to inclusions in or exclusions from the index.

The remaining of the study has the following structure. Section 2 provides a review of previous research on the CSP-CSD-CFP links, justifies the application of a configurational approach to try to disentangle past inconclusive and even contradictory results and presents ten propositions to be tested using fsQCA. Section 3 explains the choice of an SRI index and of concrete measures of CSD and CFP, describes the sample, introduces the fsQCA technique and presents the specification of causal conditions and outcomes as well as four alternative models to test the propositions. Section 4 shows and discusses the results. Finally, Section 5 identifies the main implications and the limitations of the study. 


\section{Theoretical Background}

In this section we review previous literature and formulate the study's propositions over four concrete areas: The CSP-CFP relationship, the role of CSD in relation to CFP and CSP, the relevance of SRI indices as a research object to explore the CFP-CSD-CFP nexus and the convenience of adopting a configurational approach to study the CFP-CSD-CSP interrelations.

\subsection{The CSP-CFP Link}

There is extensive research on the integration of sustainability or CSR into corporate strategic management [18], and particularly on the analysis of the links with economic value creation (including comprehensive reviews and meta-analysis [2,14,19-22]); however, the results regarding the relationship between CSR and financial performance remain inconclusive [17,23-25]. In particular, research findings support all the possible hypotheses (non-significant or neutral effects, positive effects and negative effects of CSP on CFP). Friede et al. [26] and Busch and Friede [19] develop second-level, or 'review of reviews' studies on CSP and CFP respectively, accounting for 2200 and 1214 unique or individual studies on the topic, finding an undeniable business case for CSR. Brammer and Millington [27] conclude that a curvilinear relationship exists between CSP (charitable giving) and CFP, as both low and high CSP are related to a high CFP.

Academic research has also focused on the analysis of the CFP consequences of corporate social irresponsibility (CSI), arguing that the CSI-CFP links can be stronger than the CSR-CFP links and that not distinguishing between CSR and CSI can be one of the reasons behind the contradictory results obtained in the numerous studies that explore this relationship [28,29]. A good number of moderating or mediating factors have also been explored [20] based on the assumption that companies' ability to gain competitive advantages and create economic value through sustainability is largely based on the possession of certain resources and capabilities, usually of an intangible nature [22,25,30], which are influenced by contextual factors [21].

Besides the inconclusive results of the vast literature devoted to the analysis of the CSP-CFP link, there is also a lack of consensus regarding the direction of the causality between CSP and CFP. Although previous literature has predominantly focused on the impact of CSP on CFP [14], some studies acknowledge that companies with a good CFP could have extra resources for the improvement of their CSP $[15,31-35]$ and support the existence of a bidirectional relation or virtuous circle between CSP and CFP [14,30,36-38]. However, studies on this issue present inconclusive results. In their meta-analysis of the CSP-CFP literature, Wang et al. [21], conclude that prior CSP is related to CFP but not contrariwise. We highlight the contribution by Ruggiero and Cuppertino [15], as they adopt a similar approach to ours for the measurement of CSP in terms of inclusion in or exclusion from the Global 100 Index (not an SRI index, but an annual ranking of the top 100 worldwide corporate leaders in CSR). Through a logistic regression analysis, they find a significant positive correlation between CFP and CSP, considering the mediating (more than moderating) effect of innovation.

The inconclusive results of previous literature on the CSP-CFP link have been attributed to conceptual or practical differences in the definition and measurement of both CSP and CFP, to the underlying theories to approach the CSP-CFP relationship and to the different methodologies applied [20,24,30,39]. Schaltegger and Synnestvedt [40] and Aguinis and Glavas [18] suggest that empirical studies are not conclusive due to the absence of clear theoretical frameworks. The authors highlight the importance of considering the specific CSR management deployed at each organisation because different CSR strategies or practices will result in different financial results. Differences in CSR management and CSP will also depend on business managers' perceptions and priorities towards CSR [41]. Regarding CFP measurement, both accounting and market-based measures have been used [36,42], sometimes in combination, but it is generally assumed that market measures are more able to capture the long-term value of CSR $[14,30]$ than financial ones. Regarding CSP measurement, the multidimensional and complex nature of CSR [41] has forced the approach to CSP through many alternative constructs, including one-dimensional measures related to different ESG dimensions, 
aggregated indicators, adhesion to global CSR codes or initiatives, reputation and SRI indices or rating methodologies [8,14,42,43]; however, the credibility and validity of many of these approaches have been questioned [8].

By associating CSP with the inclusion in or exclusion from a SRI index, this study avoids the controversial choice of specific measures of CSP (Kappou and Oikonomou [6] also acknowledge this advantage). This choice could seem partial, incomplete or biased in many ways, either in the form of a composite index combining different ESG factors or of different indicators of the CSP components [14,42]. Furthermore, by focusing on the effects of CFP on CSP and not the opposite, we also avoid problems related to the possible counteracting effects of different ESG issues on CFP $[23,44-46]$ that could also be behind the inconclusive results of previous research on the CSP-CFP link.

Complexity both in approaching CSP measurement and in conceptualising its impact on CFP has been largely identified as inherent to the relationship between CSP and CFP, and as a possible cause of the inconsistent results of previous literature [17,22,39]. Aguinis and Glavas [18] and Grewatsch and Kleindienst [20] claim for new theoretical frameworks and new methodological orientations in order to make meaningful advances in the CSR domain, accounting for the mediating and moderating role of diverse internal and external variables in the relationship between CSR and different types of outcomes (as CSP or CFP) and acknowledging that antecedents of CSP may operate in an interdependent manner rather than in isolation. Past literature on the CSP-CFP link has also signalled towards non-linearity and asymmetrical causation [3] as well as equifinality [27] between CSP and CFP. Thus, all these specific features have motivated the incipient application of QCA to the CSP-CFP field of research [17].

Drawing from previous literature suggesting an influence of CFP on CSP, considering our research objectives and adopting QCA as the appropriate methodological framework, we define the first proposition to be tested through a fsQCA as the two sides of the same coin:

Proposition 1a. Companies with a high CFP will also show a good CSP, which will facilitate their inclusion in an SRI index.

Proposition 1b. Companies with a low CFP will also show a poor CSP, which will favour their exclusion from an SRI index.

\subsection{The Relevance of CSD}

The analysis of the CSD-CSP-CFP links has also largely attracted the interest of academic research, which is characterized by inconclusive results associated with different theoretical, methodological and measurement approaches [2]. CSD has in fact been brought up to explain the inconclusive results of studies on the CSP-CFP link, signalling the lack of homogeneity in sustainability reports [47] or their exclusive use by a small fraction of larger companies [48] and emphasizing the confusion faced by reports users despite standardisation efforts such as the GRI [49]. The importance of CSD as a mediator or moderator of the CSP-CFP relationship has also been highlighted [3,50,51].

Previous literature analysing CSD is mainly focused on the adoption of the GRI standard [52], which has evolved through different versions of guidelines for the reporting of sustainability information (the GRI G3.1 and G4 being the latest ones). Until the release of the G4, this standard was accompanied by the possibility of distinguishing between different self-referenced application levels, substituted in the G4 by a materiality assessment provided by the GRI itself upon payment. There is also incipient research related to the Integrated Reporting (IR) framework, although its relative novelty and the slow adoption rates limits the availability of empirical research [53].

CSD has been measured through content analysis of sustainability reports [48,54,55], according to the level of compliance with GRI guidelines [56] or through ranking instruments such as Bloomberg's ESG disclosure scores [51,57]. Crifo et al. [58] used a different approach that included fictitious ESG disclosures to potential private equity investors, finding an asymmetric effect: Bad ESG information has a greater impact on firm value and investment decisions than good ESG information. 
Previous research has explored all the possible causal interactions between CFP and CSD and between CSP and CSD [2,59]. Regarding the CFP-CSD relationship, Fifka [59] finds that US studies have been more focused on the impact of CFP on CSD, with inconclusive results. Despite the inconclusive results, the positive influence of CFP on CSD appears to have received greater support $[54,57,60,61]$. Moving towards the effects of CSD on CFP, literature on the impact of global CSD (not only environmental reporting) on CFP is scarce [2] because most of the literature on the impact of CSP on CFP focuses on global CSP rather than on CSD in particular [62]. Studies on the impact of CSD on CFP show again inconclusive and even contradictory results, pointing towards equifinality, causal asymmetry and complexity between CFP and CSD. Several studies find some evidence of a positive relationship between CSD and CFP [55,62]. Other studies addressing the CSP-CSD-CFP interrelations find a negative effect of CSD on firm value [51] or no effect [3]. There is also a strand of research dealing with the bidirectional links between the quality of sustainability reporting and financial reporting [56,63]. Studies exploring the effects of CFP on CSD are usually based on accounting measures of CFP under the slack resources theory [38,64], assuming that companies with a good CFP will devote more resources towards and improved CSD and CSP. By contrast, studies focused on the impact of CSD on CFP are mainly based on market-based measures of CFP to explore the value relevance of CSD for stock markets and its potential impact on the reduction of information asymmetry and the cost of capital [50].

Regarding the CSP-CSD relationship, the effects of CSP on CSD have received a great part of the attention, but they are not clear from a theoretical standpoint, because good CSR performers have natural incentives to improve their disclosure and reduce information asymmetry [50] and to differentiate from bad CSR performers [65]. Nevertheless, bad CSR performers can also look for legitimacy through CSD [66]. Fifka [59] also reports inconclusive results of US studies focused on the impact of CSP on CSD. Schreck and Raithel [65] report a strong non-linear relationship between CSP and CSD and Hummel and Schlick [67] find a significant positive (negative) relationship between CSP and high-quality (low-quality) CSD.

The impact of CSD on CSP has rarely been explored in previous literature [12,13]. There are different arguments that support the positive effect of CSD on CSP. Topping [13] analyses how engagement with the Carbon Disclosure Project is expected to change corporate behaviour towards an improved CSP due to different motivators or drivers: (1) What gets measured gets managed, (2) changes in strategic thinking brought about by disclosure, (3) external demands to compare CSP across companies or industries, (4) competitor benchmarking and (5) SRI. Christensen [12] finds that CSD reduces the probability of being involved in CSI and that reporting companies involved in CSI experience lower negative stock price impacts compared to uninvolved companies.

We position our study in this under-researched area of the impacts of CSD on CSP assuming that CSD and the pressure of an increased scrutiny and demand of non-financial information are drivers of CSP. In our study, CSP is derived from inclusions in or exclusions from an SRI index; in addition, we assume that a good CSD facilitates inclusion in an SRI index and that a poor CSD leads to exclusion. Again, the review of previous research on the CSP-CSD-CFP links has evidenced signs of complexity, causal asymmetry and equifinality that justify a configurational methodological approach. We define the second proposition to be tested through a fsQCA as:

Proposition 2a. Companies highly committed to CSD will also show a good CSP, which facilitates their inclusion in an SRI index.

Proposition 2b. Companies with a low or no commitment to CSD will also show a poor CSP, which contributes to their exclusion from an SRI index.

\subsection{SRI Indices}

The growing interest on CSR, ESG or corporate sustainability issues and the development of SRI has triggered the appearance of many sustainability or SRI indices that have been also studied under the CSP-CFP research field. As Searcy and Elkhawas [11] acknowledge, the best known and most 
mentioned in academic literature are the Dow Jones Sustainability Index series (DJSI), the FTSE4Good Index series and the MSCI ESG Index (formerly KLD and Domini 400 Social Index).

SRI indices have been widely used in the CSP-CFP literature as proxies for CSP [3], assuming that companies listed in an SRI index have a good CSP and that companies not included have a poor CSP; however, it has been criticised for the rather obscure methodologies behind the indices' configuration and management, and the potential existence of other factors apart from CSP influencing inclusions in and exclusions from the indices [8-10]. Once again, studies offer inconclusive results, from no effect on CFP to both positive and negative relations. Eom and Nam [68] analyse the impacts of being included in an SRI index on cost of equity and firm value (Tobins' $Q$ ) and find mixed results: No relation for the entire sample, and differences depending on the time of the inclusion, so that inclusions when the index was created showed a negative relation to cost of equity, whereas those related to revisions of the index showed a positive relation. Finally, we highlight the contribution by Ziegler and Schröder [10], as it is quite close to this study's aim. They examine the antecedents of inclusions in two indices of the DJSI family and find an ambiguous influence of CFP measures (with some support to the slack resources theory) but a significant influence of other factors different from CSP, related to the sustainability assessment and selection processes for the composition of the indices, and questioning the reliability of inclusions in SRI indices as proxies for CSP.

A different approach compares the performance of SRI indices with conventional ones; these studies mostly find no significant statistical differences in risk-adjusted returns [69,70]. Nevertheless, Consolandi et al. [71] show higher returns for the DJSI compared with a surrogate complementary index. In any case, these studies represent only a small fraction of a greater set of studies focusing on the performance of SRI strategies against traditional investment strategies, showing heterogeneous results that have been also converging throughout time towards the no cost or benefit conclusion [7].

Of greatest interest in the context of this study is the academic literature based on the analysis of the impact of inclusion/exclusion on CFP, usually instrumented through event studies looking for any significant stock price reaction to the announcement of the inclusion in or exclusion from an SRI index. A general interesting conclusion of these studies is that exclusions have a greater impact on CFP compared to inclusions [4,6,71,72]. In fact, Doh et al. [4], Kappou and Oikonomou [6] and Oberndorfer et al. [72] do not find any significant market reaction to inclusions, but confirm negative reactions to exclusions, whereas Consolandi et al. [71] also find a positive reaction to inclusions, but softer than for exclusions. Russo and Mariani [73] only focus on exclusions also confirming negative impacts on CFP (Tobins' $Q$ and stock return). Other studies find limited evidence of significant impacts of SRI indices' inclusions and exclusions on stock returns $[5,74,75]$.

In their event study, Doh et al. [4] also analyse the moderating role of previous operating performance (operating income to total assets ratio) and previous CSR reputation over the impact of inclusions and exclusions on CFP. They find that companies included (excluded) in (from) an SRI index had higher (lower) previous operating performance than excluded (included) ones. Regarding the influence of previous CSR reputation, a stronger reputation mitigates the negative impact of exclusions on market value but also the positive effect of inclusions. Doh et al. [4] explicitly advocate the identification of inclusions in and exclusions from an SRI index with good or poor CSP.

This review of previous research reveals that inclusions in and exclusions from SRI indices have been mainly used in the context of event studies to verify some market reaction to those announcements. Little research has explored the underlying reasons of inclusions or exclusions. Russo and Mariani [73], in their event study on exclusions from the FTSE4Good Index, analyse the effect of exclusions motivated by failure to meet any of the five different sustainability criteria reported by FTSE4Good itself, concluding that only countering bribery has a significant impact on CFP. Ziegler and Schröder [10] focus only on inclusions to analyse the role of CFP (and other geographical and time factors related to the internal assessment process of the rating agency behind the SRI index) as determinants of inclusions. They also question whether inclusions are really equivalent to a good CSP. 
The study of Doh et al. [4] is also relevant, although they do not analyse antecedents of inclusions or exclusions, but moderating factors of their impact on CFP.

To our knowledge, no previous research has analysed CSD as an antecedent of inclusions to or exclusions from SRI indices. As we have previously argued, CSD is essential for SRI strategies in general and for the configuration of SRI indices in particular. We also provide a more ample approach than previous research by jointly studying both inclusions and exclusions because Russo and Mariani [73] only analyse exclusions and Ziegler and Schröder [10] only focus on inclusions. Therefore, this study focuses both on inclusion and exclusion events to examine the role of CFP and CSD as antecedents of CSP, trusting in the validity of those inclusions and exclusions as expressions of a good or poor CSP. In comparison to studies using being listed in an SRI index as proxy for a good CSP and not being listed as proxy for poor CSP, our approach (shared by the majority of event studies) can be considered more robust because poor CSP is identified with being delisted. We consider that exclusion from the index is more indicative of a poor CSP than just not being listed.

Another important contribution of our study is the selection of the inclusion and exclusion events of the sample. As in Eom and Nam [68], we distinguish between the time of creation of the SRI index and the subsequent revisions. Furthermore, we analyse only inclusions or exclusions that have been preceded by a former exclusion or inclusion. This implies that inclusions at the time of creation of the SRI index are not considered in our analysis. This gives us the opportunity to analyse how changes in CFP can be related to changes in CSP, assuming that an improvement in CSP provoking an inclusion in a SRI index after a previous exclusion can be accompanied by an improvement of CFP, and that a deterioration of CSP causing an exclusion is likely in combination with a worsening of CFP.

Thus, in Proposition 1a. and Proposition 1b., we analyse CFP from a static perspective (considering specific CFP measures at a point of time), whereas the next alternative, although complementary, propositions follow a dynamic perspective (based on changes in CFP indicators). Both options seem justified: Better financial conditions at a particular moment can facilitate both better CSD and CSP and the inclusion in an SRI index, while the inclusion/exclusion event could be also explained by an increase/decrease in CFP indicators between the event year and that of the previous exclusion or inclusion. Drawing from previous literature on the antecedents and effects of SRI indices' inclusions and exclusions, we conclude one more time that asymmetry, equifinality and complexity are likely to be present in the analysis of the relationships between CFP and CSP (inclusions in or exclusions from an SRI index). Therefore, the study is based on a configurational framework. The third proposition to be tested through a fsQCA is as follows:

Proposition 3a: Companies that experience an improvement in their CFP (increase in CFP indicators) will also show a better CSP, which will facilitate their inclusion in an SRI index.

Proposition 3b: Companies that experience a worsening of their CFP (decrease in CFP indicators) will also show a poorer CSP, which will contribute to their exclusion from an SRI index.

\subsection{A Configurational and Complexity Theory Approach to Analyse the Relationship between CSD, CSP and CFP}

The inconclusive results or previous academic literature exploring the links between CSP, CSD and CFP are probably explained by the existence of non-linear, asymmetrical and complex relationships among these concepts. If we want to investigate the influence of CSD and CFP on CSP (Proposition 1a., 1b., 2a., 2b., 3a. and 3b.), it seems advisable to study how CSD and CFP combine rather than compete to explain CSP (inclusion in or exclusion from an SRI index).

While previous literature mainly relies on the application of multivariate regression analysis or other similar techniques based on the assumption of a symmetrical relationship between variables, this study employs a different methodology to analyse how CSP (inclusion in or exclusion from an SRI index) can be explained by different combinations of CSD and CFP factors. Qualitative comparative analysis (QCA), proposed by Charles Ragin [76-79], is a half qualitative - half quantitative method based on the use of Boolean algebra to deal with causal complexity and identify configurations, 
paths or combinations of causal conditions that are necessary or sufficient to explain a specific level of an outcome $[80,81]$. In the context of QCA, the concepts of outcome and causal conditions are used to refer to the dependent and independent variables of traditional techniques, but the idea of causality is rather different. In contrast to regression and correlation methods, where each causal condition has an independent impact on the outcome, QCA searches for a combined and not uniform causation where several conditions combined may be present in the outcome, and the same causal conditions may act in favour for or against the outcome [82].

QCA is built upon the foundations of configurational or set analysis and complexity theory [17]. The configurational or set approach explores the different combinations or sets of causal conditions leading to an outcome in terms of sufficiency and necessity [78,79], whereby a condition or set of conditions are necessary if they are present in all instances of the outcome (outcome $Y$ always involves condition $\mathrm{X}$ ) and they do suffice if a particular outcome appears whenever the condition or set of conditions are present (condition $X$ always implies the presence of outcome $Y$ ) $[16,83,84]$. Complexity theory proposes a higher number of complex relationships than of cause-effect relationships between causal conditions and outcomes [85]. Complexity theory assumes some fundamental principles, mainly the following ([79-82,85-88]): (1) Equifinality implies that different combinations of causal conditions can lead to the same outcome; (2) asymmetry assumes that one causal condition can simultaneously explain high and low levels of the outcome; (3) complexity or conjunctural causation imply that the influence of causal conditions on outcomes depends on the presence or absence of other causal conditions; and (4) causal asymmetry means that causal conditions that lead to the outcome might be different from those leading to the absence of the outcome. QCA allows dealing with this equifinality, asymmetry, complexity and causal asymmetry principles studying multiple conjunctural causation patterns among causal conditions and outcomes [77,82].

There are three QCA variants [16]: Crisp-set QCA (csQCA), which treats each case or observation from a sample as being in or out of the set of cases for each causal condition or outcome, and allocates membership scores of 0 or 1 ( 0 indicates non-membership, and 1 represents membership); multi-value QCA (mvQCA), which allows multi-value conditions (each category is represented by a natural number in an ordinal scale); and fuzzy-set QCA (fsQCA), which uses membership scores between 0 and 1 through a calibration process. FsQCA is the most applied technique $[16,89]$. Furthermore, crisp and fuzzy sets may be combined [84].

Although QCA was originally designed for small-N studies, the development of QCA from crisp sets to fuzzy sets and improvements in the underlying software algorithms have opened the door to its application to large-N studies [81,84], which has contributed to its application to management studies $[16,89]$. FsQCA can provide important insights into areas of research where causal relationships are expected to be heterogeneous across cases [83]. Kan et al. [89] highlight that an important part of the management literature applying QCA, tries to legitimize its use by comparing its application with traditional empirical methods, or to review commonly accepted links that existing theories do not sufficiently explain.

Some pioneering empirical research has started to apply fsQCA in the CSR, ESG or CSP domains $[83,85,90-93]$. Because of their focus on the influence of ESG-related factors on financial performance, or their analysis of SRI indices, five contributions applying fsQCA are closest to this study's aim. Wang et al. [94] explore the sufficiency conditions of reputation in explaining firm's market value (common stock price), using three reputation-measurement instruments together with book value and EPS. Paniagua et al. [95] analyse the impact on ROE of diverse corporate boards and firm characteristics, and find an interesting exception to the general rule where higher leverage and property dispersion demand an extended board of directors to reach a higher ROE. Primc and Čater [96] test the influence on firm performance (composite index of perceptual financial and non-financial measures) of companies' environmental proactivity, life-cycle stage, and the uncertainty, complexity and munificence of the business environment. Slager [84] applies fsQCA to the FTSE4Good SRI index to analyse listed companies' reactivity (improvement on scores of the FTSE4Good criteria in 
order to remain included), considering as causal conditions the degree of engagement with the FTSE Responsible Investment team, the number of years in the index and whether the company has ever been excluded or not from the index, gives publicity to the inclusion and is classified by the FTSE4Good as having high or low CSR- related risks. Finally, Isaksson and Woodside [17], develop a comprehensive study of the heterogeneous relationships that condition the CSP and CFP link, stating that good or bad management needs to be considered together with CSP in order to explain CFP. They test 27 different propositions through alternative fsQCA model specifications, concluding that there is more evidence of the influence of bad management and the negation of CSP on negative CFP than of high overall CSP supporting high CFP outcomes.

This study, therefore, applies the fsQCA technique to explore the necessary and sufficient conditions of CSD and CFP that explain CSP (being included in or excluded from an SRI index) and to analyse whether different CSD and CFP factors are able to jointly or individually explain CSP. This analytical choice allows us to study the diversity of causal paths leading to an inclusion in or exclusion from an SRI index (associated to a good or poor CSP) and to explore how CSD and CFP combine to describe or explain a company's entry or exit.

This is a preliminary and exploratory study aimed at both testing the validity of the fsQCA methodology for the analysis of the corporate sustainability and financial performance link, and searching for complex relations that offer avenues for further research. Therefore, we define some additional propositions that uncover the presence of the main principles of complexity theory according to Woodside [88]. Following Cuadrado-Ballesteros et al. [85] we suggest four additional propositions to be explored through a fsQCA model relating CSD, CFP and CSP (entering/exiting an SRI index):

Proposition 4. Entering (or exiting) the index can be achieved through different configurations of CSD and CFP (equifinality).

Proposition 5. The effect of a condition on the inclusion in or exclusion from the index depends on other conditions (complexity).

Proposition 6. Configurations associated with exclusion from the index are not the mirror opposite of those associated with inclusions in the index (causal asymmetry).

Proposition 7. The same CFP and CFP characteristics can contribute both to the inclusion in and exclusion from the index (asymmetry).

These four additional propositions will provide a deeper and better understanding of this study's results regarding Propositions 1a., 1b., 2a., 2b., 3a. and 3b. In particular, insofar as fsQCA specifies alternative models to analyse both the presence and the absence of the outcome (good CSP or inclusions in an SRI index and poor CSP or exclusions from a SRI index), proposition 7 is meant to confirm that Propositions 1b., 2b. and 3b. are not just the mirror opposite of Propositions 1a., 2a. and 3a.

\section{Data and Methodology}

In this section we first present and justify the choice of one of the numerous SRI stock indices available and of specific measures of CFP and CSD. Next, we explain how we have defined and configured the sample and provide some descriptive information. Then, we outline the methodological foundations of the fsQCA, while the last subsection reports the fsQCA variables (outcome and conditions) and the alternative model specifications.

\subsection{Selection of an SRI Index}

There are many sustainability, CSR or ESG-related stock indices, based on different investment universes regarding their geographical scope and their relation to general or specific ESG topics [9]. The United States equity market is of particular interest when analysing investment strategies and results, given its strong efficiency and well-established institutional dynamics, and considering that it is a reference market worldwide and a barometer of the US economy in particular, and of the whole world economy generally $[97,98]$. Regarding the relevance and importance of ESG matters in the US 
capital markets, although in the US, corporate sustainability reporting remains on a voluntary basis, and reporting rates are under the European and Asian ones [99], its business environment seems more demanding of this type of information [100]. US companies are assumed to develop an explicit or more strategically integrated CSR, compared to an implicit CSR in Europe, oriented towards meeting societal expectations [101]. By focusing on the US market, we leave aside the effect of different institutional, cultural and legal environments $[62,85]$ that could condition the CSP-CFP relationship.

The study uses the US stock market S\&P 500 index, managed by the S\&P Dow Jones Indices company because it provides a wide representation of the US market, capturing approximately $80 \%$ coverage of available market capitalization [102]. The Government \& Accountability Institute [103] has analysed the S\&P 500 constituents' sustainability reporting activities from 2011 onwards, and has found that sustainability reporting has risen from just $20 \%$ of the companies reporting in 2011 , to $85 \%$ in 2017. Consequently, the S\&P 500 index seems an appropriate reference context to fulfil the goal of this study. Tamimi and Sebastianelli [104] offer a complete analysis of the CSD of S\&P 500 companies focusing on their Bloomberg ESG disclosure scores.

The S\&P Dow Jones Indices company has launched a good number of sustainability-related stock indices with different foci and eligible universes (118 indices were shown in July 2018 on its web), but only two have the S\&P 500 index as their underlying index in relation to global sustainability or ESG issues: The S\&P 500 Environmental and Socially Responsible Index (S\&P 500 E\&S) and the S\&P 500 ESG Factor Weighted Index (S\&P 500 ESG). Both indices use ESG scores provided by the investment and rating agency RobecoSAM, but while the former is a standard capitalisation-weighted index, the latter is a smart-beta index that bases its composition on ESG factor scores proposed by RobecoSAM.

RobecoSAM develops an annual process of Corporate Sustainability Assessment (CSA), which is also the basis for the Dow Jones Sustainability Indices (DJSI) family, and is based either on a questionnaire proposed to companies, or on publicly available information [9]. For the S\&P 500 E\&S, RobecoSAM provides an Environmental and Social (E\&S) Score that is the weighted average of the scores for the Environmental and Social dimensions received during the CSA process. For the S\&P 500 ESG, RobecoSAM provides total scores (or classic scores, also used in the DJSI) that are the weighted average of the scores for the Environmental, Social and Economic dimensions assessed through the CSA.

One main difference between the two indices regarding their eligible universe, is that the S\&P $500 \mathrm{E} \& S$ excludes companies involved in fossil fuel-heavy industries or in the production and sale of tobacco, cluster bombs, landmines, nuclear and other military armaments. Then, the selection of index constituents in the S\&P $500 \mathrm{E} \& S$ starts sorting the rest of companies of the S\&P 500 by 11 GICS sectors and then by E\&S Scores, selecting companies in decreasing order till reaching $75 \%$ of the float-adjusted market capitalization in each sector. For index calculation, constituents are weighted by free float market capitalisation. The S\&P 500 ESG transform the classic scores derived from the CSA into ESG factor scores under a smart-beta approach, trying to prioritize financial materiality and to neutralize the effect of biases such as GICS industries, sub-industries and countries as well as investment factors as momentum, value and size.

As a result of these methodological differences, the S\&P 500 ESG index is not well-suited for the purpose of our study, as its constituents are practically the same as those of its underlying index (as of 29 June 2018, the S\&P 500 showed 505 constituents and the S\&P 500 ESG 494). Given that we want to analyse inclusion and exclusion events, the S\&P 500 E\&S index (with 292 constituents in the same date) is the obliged choice. Furthermore, we understand that the philosophy behind the S\&P 500 ESG does not correspond with the aim of this study, as it is much more investment-oriented through a specific investment strategy (smart-beta strategy). To our knowledge, this study, together with López-Cabarcos et al. [105], are the first academic studies focusing on the S\&P 500 E\&S index. 


\subsection{Measures of CSD and CFP}

Drawing from the review of previous research and on the study's objectives formalised in Propositions 1a., 1b., 2a., 2b., 3a. and 3b., we have selected different variables to be considered as causal conditions in an fsQCA.

CSD is analysed through three dichotomous variables and a continuous one: Being included or not in the GRI sustainability disclosure (GRI SD) database, having or not having a sustainability report about the year before the inclusion or exclusion event, and whether this report explicitly follows some of the GRI standards as dichotomous variables, and the number of published sustainability reports registered on the GRI SD database as continuous variable. The use of the GRI sustainability reporting guidelines is generalised worldwide; it is the most common standard among reporting companies $[52,106,107]$, and the GRI SD database is a common reference to define study samples in the analysis of the CSP-CSD-CFP links [55,56,62,108]. Considering whether sustainability reports are or not compliant with some of the alternative versions of the GRI guidelines is indicative of reporting quality [56]. Given the exploratory nature of this study, and the need to limit the number of causal conditions included in the fsQCA, we have decided to consider the adherence to the GRI standards globally (similar to Goettsche et al. [62]) without distinguishing between externally assured or non-assured reports, GRI guidelines' version or application levels (in contrast to previous studies $[3,56,63,108])$. Moreover, within the period of 2010-2016, many companies changed the format of their reports (from compliant to non-compliant with GRI guidelines or the opposite, and also across different application levels and assured or non-assured states), so that it would be difficult to account for this in the fsQCA. Consequently, we only verify adherence to the GRI guidelines regarding reports available for the year before the inclusion or exclusion event. The availability of a report referred to the year before the inclusion or exclusion event is considered informative, as it is expected that without such relevant disclosure companies previously included in the index could be excluded. Finally, the number of published reports registered at the GRI SD database or reporting frequency has also been used in previous studies [108] to evaluate the intensity of a company's commitment with CSD. We consider the total number of reports reflected in the GRI database for each company entering or exiting the index, irrespective of whether these reports are adhered to the GRI guidelines, or of the different application levels. According to Proposition 2a., we expect that companies included in the GRI SD database that have published a report referred to the previous year of that of the entry or exit event, that follow the GRI guidelines and that have a high number of reports registered at the GRI SD database will exhibit a high CSP and thus represent a high proportion of the companies that experience an entry event. On the other hand, according to Proposition $2 b$., we expect that companies not included in the GRI SD database (so that the rest of CSD variables will be absent) will exhibit a poor CSP and thus represent a high proportion of the companies that experience an exclusion event.

CFP can be measured through accounting or market measures. Accounting measures are interesting in the analysis of the sustainability-financial performance link, because they can reflect financial consequences of sustainability practices (amount of investment devoted to sustainability, costs and revenue derived from sustainability practices) and even preconditions to sustainability efforts (more financially-sound companies can be more involved with sustainability matters). Market measures are also interesting, but a bit more complex to deal with in order to extract straightforward conclusions, as they are based on expectations and these can be influenced by past, current and expected sustainability and financial performances. In this study, CFP is analysed both through accounting and market measures, choosing the absolute revenue figure and the earnings per share (EPS) ratio as accounting measures of CFP, and the price-earnings ratio (PER) as market measure. Although these indicators are not the most commonly used in previous literature, different literature reviews on the CSP-CSD-CFP links document the use of these alternative measures [20] and indicate mixed results regarding the sense (positive or negative) and direction of causality. We choose revenue and EPS as we assume that the possibility of developing a good CSD and achieving a good CSP is related to the availability of financial resources. The PER ratio allows us to introduce in the analysis 
the possible effect of market expectations regarding companies' CSP, as well as to control for the possible effect of a higher or lower market capitalisation on the inclusion in or exclusion from the SRI index. We use both the value of these indicators at the event year, as well as the change that they have experienced in the period between an entry event and the previous exclusion from the index or between an exit event and the previous inclusion in the index. Given that we are trying to explain why a company is included again in the S\&P 500 E\&S index after having been excluded, or why a company is excluded from the index after its inclusion (without considering the initial index configuration), this way of approaching the measurement of CFP could yield interesting results. This is a rarely applied approach for the measurement of CFP in previous literature on the relationships of CFP with CSD or CSP. Its application is derived from our distinct and novel approach in this study focusing on companies that have experienced a decline in their CSP (exit the S\&P 500 E\&S index after a previous inclusion event), or that show an improvement in their CSP (entry the S\&P 500 E\&S index after a previous exclusion event).

Considering CFP dynamically allows us to deal with the debate on CSP and CFP concurrency in time [14]. In contrast to Ruggiero and Cuppertino [15], we do not consider any time lag as we are neither looking for causality between CFP and CSP, nor explicitly advocating the slack resources theory (although it does influence our choice of CFP measures), that is, we do not want to test if the availability of extra resources in one year increases CSP the following year. Instead, we want to test whether a high CSP leading to an inclusion in an SRI index is accompanied by a high CFP (Proposition 1a.) or an improved CFP (Proposition 3a.), and whether a poor CSP leading to an exclusion from a SRI index is accompanied by a low CFP (Proposition 1b.) or a decrease in CFP (Proposition 3b.). Although our contemporaneous measurement of CSP and CFP is justified because we are looking for associations but not for causality, it has been acknowledged that CSP and CFP can under some circumstances be related at the same point in time [14], as long as concurrent measurement does not imply absolute simultaneity, and using a market measure does not impede the interpretation of causality, as we can assume that the PER ratio reflects expectations on future CSP and CFP. Regardless, also considering the change experienced in CFP between two consecutive inclusion and exclusion events, allows us to some extent to account for long-term or deferred effects of CFP on CSP.

Finally, as an additional casual condition, we consider the number of years between an entry event and the previous exit, or between an exit event and the previous entry, assuming that a long period is needed to cause a significant change in the CSP of a company that leads to an inclusion in the S\&P 500 E\&S index after a previous exclusion, or to an exclusion after a previous inclusion. Note that this variable measures the period of inclusion for exclusion events (that is, number of years a company had been included in the S\&P 500 E\&S index before being excluded) and the period of exclusion for inclusion events (number of years a company remained excluded before being included again).

\subsection{Sample and Data Collection}

The S\&P 500 E\&S index was launched in May 2015 with a first value date of 30 September 2010. Table 1 shows the evolution of the number of constituents of the S\&P 500 E\&S index and the S\&P 500 during the period 2010-2016. Using the data of companies listed in the S\&P 500 and the S\&P 500 E\&S during this period, we identified companies' entries and exits in both indices and generated a database comprising only those entries subsequent to the index's first configuration of 2010 (that is, entries from 2011 onwards) that do not correspond to new listings in the underlying index (S\&P 500), and only those exits not related to a delisting or removal from the S\&P 500 .

We have registered a total of 440 companies that were listed at some point in the S\&P 500 E\&S index in the period 2010-2016 (checked over end-of-year lists of constituents); 237 of them were present at the initial configuration of the index in 2010. These companies have been involved in 488 index inclusion and exclusion events after its initial configuration. In order to consider only the inclusion in the index after a previous exclusion, or the exclusion from the index after a previous inclusion, the inclusions that were not preceded by an exclusion event and all exclusions that happened after the 
inclusion at the initial configuration of the index were removed from the sample. Furthermore, we did not consider inclusions or exclusions motivated by a corresponding inclusion in, or exclusion from the underlying index (S\&P 500).

Table 1. Companies listed at end of each year (2010-2016).

\begin{tabular}{ccc}
\hline Year & S\&P 500 & S\&P E \\
\hline 2010 & 500 & 237 \\
2011 & 500 & 229 \\
2012 & 500 & 243 \\
2013 & 500 & 258 \\
2014 & 502 & 275 \\
2015 & 504 & 284 \\
2016 & 505 & 284 \\
\hline
\end{tabular}

After this process, the sample comprises 126 events, 65 of which correspond to inclusions after a previous exclusion, and 61 to exclusions after a previous inclusion. These 126 events correspond to 99 different companies. Table 2 shows the distribution of these 99 companies by GICS sector, with the Financials and Information Technology categories being the most represented sectors, with 17 companies each one, and the Telecommunications Services category not being represented at all.

Table 2. Distribution of companies by GICS sector.

\begin{tabular}{ccc}
\hline GICS Sector & $\begin{array}{c}\text { Number of Companies in } \\
\text { the Sample }\end{array}$ & $\begin{array}{c}\text { Number of Companies Included } \\
\text { in the GRI Database }\end{array}$ \\
\hline Financials & 17 & 11 \\
Information Technology & 17 & 11 \\
Consumer Discretionary & 16 & 10 \\
Consumer Staples & 13 & 13 \\
Industrials & 10 & 8 \\
Health Care & 6 & 4 \\
Materials & 6 & 5 \\
Utilities & 5 & 5 \\
Real Estate & 5 & 5 \\
Energy & 4 & 3 \\
Total & 0 & 0 \\
Telecommunication Services & 99 & 75 \\
\hline
\end{tabular}

Of the 99 companies, 75 are included in the GRI SD database (see also Table 2 with distribution by GICS sector), two have 15 sustainability reports registered at the database, and another one has 14 . The majority of companies have between two and five registered sustainability reports (49), while only six companies have only one registered sustainability report at the GRI database. For 66 events, there were sustainability reports referred to the previous year at the GRI database (corresponding to 53 companies) but only 37 (corresponding to 28 companies) were adjusted to GRI standards.

Table 3 shows the distribution of entry and exit events by year and GICS sector. The year 2016 has the highest number of registered events (44), while 2012 has only 11; the 'Financials' and 'Consumer Staples' GICS sectors are the most represented (21 and 20 events), while the 'Energy' (6), 'Utilities' (6) and Heath Care (7) sectors are the least represented ones. 
Table 3. Number of events by year and GICS sector.

\begin{tabular}{ccccccc}
\hline GICS Sector & $\mathbf{2 0 1 2}$ & $\mathbf{2 0 1 3}$ & $\mathbf{2 0 1 4}$ & $\mathbf{2 0 1 5}$ & $\mathbf{2 0 1 6}$ & TOTAL \\
\hline Financials & 2 & 8 & 4 & 2 & 5 & 21 \\
Information Technology & 1 & 0 & 6 & 2 & 9 & 18 \\
Consumer Discretionary & 1 & 0 & 3 & 4 & 8 & 16 \\
Consumer Staples & 5 & 3 & 6 & 2 & 4 & 20 \\
Industrials & 0 & 1 & 2 & 3 & 6 & 12 \\
Health Care & 0 & 0 & 1 & 3 & 3 & 7 \\
Materials & 1 & 3 & 2 & 2 & 2 & 10 \\
Utilities & 0 & 3 & 0 & 1 & 2 & 6 \\
Real Estate & 1 & 0 & 4 & 2 & 3 & 10 \\
Energy & 0 & 2 & 1 & 1 & 2 & 6 \\
TOTAL & 11 & 20 & 29 & 22 & 44 & 126 \\
\hline
\end{tabular}

Table 4 shows the distribution of events both by event type (exit or entry) and event year. Finally, regarding the number of years that have passed between an inclusion event and the previous exclusion (exit-entry event) or and exclusion event and its previous inclusion (entry-exit event), most events involve just one year between inclusion-exclusion or exclusion-inclusion events (60 events), 32 events accumulate two years, 22 events accumulate three years, seven events accumulate four years and five events accumulate five years.

Table 4. Distribution of events by event type and year.

\begin{tabular}{cccccc}
\hline Event Type & $\mathbf{2 0 1 2}$ & $\mathbf{2 0 1 3}$ & $\mathbf{2 0 1 4}$ & $\mathbf{2 0 1 5}$ & $\mathbf{2 0 1 6}$ \\
\hline Exits & 2 & 11 & 14 & 11 & 23 \\
Entries & 9 & 9 & 15 & 11 & 21 \\
\hline
\end{tabular}

CFP data about revenue and EPS were collected through the Edgar Online database, while data about historical stock prices were retrieved from the Nasdaq's website. Table 5 shows a summary of the statistics for the 126 events.

Table 5. Summary statistics of CFP variables.

\begin{tabular}{ccccc}
\hline CFP Measure & Mean & Std. Dev. & Max & Min \\
\hline Revenue (event year) & $\$ 21,293.10$ & $\$ 33,827.04$ & $\$ 179,770.00$ & $\$ 984.36$ \\
EPS (event year) & 3.52 & 4.31 & 40.70 & -4.64 \\
PER (event year) & 18.71 & 86.23 & 422.25 & -843.09 \\
Variation in revenue & $10.70 \%$ & $34.79 \%$ & $285.26 \%$ * (increase) & $0.09 \% *$ (increase) \\
Variation in EPS & $18.67 \%$ & $179.25 \%$ & $1,275.00 \% *$ (decrease) & $0.56 \%$ * (increase) \\
Variation in PER & $33.92 \%$ & $406.44 \%$ & $3,692.32 \% *$ (decrease) & $0.05 \% *$ (increase) \\
\hline
\end{tabular}

\subsection{Fuzzy-Set Qualitative Comparative Analysis}

Following Ragin [79], the first step in QCA is a purposeful and well-founded selection of cases, with a clear definition of the outcome to delineate the sample, while trying to guarantee that cases are comparable, and presenting enough variance in their causal conditions to infer conclusions about patterns and trends [84].

The second step is the calibration of each case's characteristics (outcome and conditions) into sets. These can be crisp and/or fuzzy sets [92], requiring the identification of the critical levels for considering full membership, non-membership and the cross-over or ambiguity point. These critical levels should be based on qualitative and substantive knowledge of each characteristic [90].

After coding data, we enter the analytical phase conducting a necessity and a sufficiency analysis [83]. Necessary conditions are those present in all cases that display the outcome, and sufficient 
conditions are those that always lead to a particular outcome [92]. Necessary conditions are not always sufficient to produce the outcome by themselves, and sufficient conditions may not be the only conditions that lead to a particular result, so there may be multiple sufficient causes that combine, creating a specific configuration or path leading to a specific result for a specific set of cases. The sufficiency analysis is developed both in relation to the outcomes' presence and absence [84].

Two measures are defined to analyse the necessity or sufficiency of causal conditions and their combinations: Consistency and coverage. Consistency refers to the degree to which the cases sharing a given combination of conditions coincide in producing the outcome $[83,85]$. A low consistency indicates that a configuration is not supported by empirical evidence [16]. The researcher must select a cut-off consistency value to decide which paths to include in the final solution [92]. Coverage refers to the number of cases for which a configuration is valid [16], that is, the proportion of cases following a specific path [83]. Low configuration coverages are common when there are many causal configurations, so it is assumed that they do not imply less relevance as the path is useful to explain a number of cases in which the outcome takes place $[16,84]$. Thus, high consistency is more important than high coverage [94].

FsQCA provides three types of solutions which show different sets of paths [83,92]: A complex solution where the software makes no simplifying assumptions, hence the most appropriate; a parsimonious solution, which uses the remainders (i.e., combinations of the antecedent conditions not observed in the dataset) to simplify the solution and should only be used if the assumptions are fully justified; and an intermediate solution, which distinguishes between "easy" and "strong" assumptions and simplifies the solution only considering the "easy" remainders.

Finally, the alternative configurations or paths leading to the outcome's presence or absence must be interpreted according to the knowledge of the cases as well as the theoretical or practical foundations.

\subsection{Model Specification}

Given that we want to analyse the paths through which CSD and CFP contribute to CSP, CSP is the outcome of the fsQCA models to be tested in this study. This outcome is defined in relation to the inclusion and exclusion events involving the S\&P 500 E\&S index after a previous exclusion or inclusion, considering that inclusion reflects a good CSP and exclusion corresponds to a poor CSP. In this way, the outcome of the fsQCA is operationalised through a binary variable that takes value 1 for inclusions (after a previous exclusion) and value 0 for exclusions (after a previous inclusion), so that the presence of the outcome (good CSP) is equivalent to being included in the index after a previous exclusion, and the absence of the outcome (poor CSP) corresponds to being excluded from the index after a previous inclusion.

The study comprises the following conditions (including four conditions of CSR disclosure, six of financial performance, and one additional condition that accounts for the time elapsed between inclusion/exclusion and previous exclusion/inclusion): (1) A binary condition that takes value 1 if the company is included in the GRI SD database, and value 0 otherwise ("GRI"); (2) a binary condition that takes value 1 if the company has published a sustainability report in the event year (referred to the previous year), and value 0 otherwise ("ReportEvent"); (3) a binary condition that takes value 1 if the report is in accordance with the GRI Guidelines, and value 0 otherwise (ReportGRI); (4) the total number of sustainability reports available at the GRI SD database for the company ("fs_noreports"); (5) the company's revenue in the event year ("fs_rev"); (6) the company's earnings-per-share ratio in the event year ("fs_eps"); (7) the company's price-earnings ratio in the event year ("fs_per"); (8) the variation in revenue between the event year and the year of the previous inclusion or exclusion ("fs_revenuevar"); (9) the variation in EPS between the event year and the year of the previous inclusion or exclusion ("fs_epsvar"); and (10) the variation in PER between the event year and the year of the previous inclusion or exclusion ("fs_pervar"); (11) the number of years between the outcome of being included in or excluded from the index, and the year of the previous inclusion or exclusion ("fs_noyears"). 
These six financial conditions are used to test two different models: Model I. includes static financial variables in the event year (Conditions 5., 6. and 7.), and Model II. includes dynamic financial variables between the event year and the year of the previous inclusion or exclusion (Conditions 8., 9 . and 10.).

This study uses the direct calibration method [79]. Due to a lack of theoretical specifications of "high" versus "low" scores, calibration of "noyears" and "noreports" and the six financial conditions followed the distribution of the actual data. We use the 95th, 5th and 50th percentiles [92,94] to determine full membership, full non-membership and the crossover point, respectively.

After calibrating the conditions, the analysis identifies the necessary conditions for being included in the S\&P 500 E\&S index (CPS), and the necessary conditions for being excluded from the index ( CPS). Here " $\sim$ " represents the absence of the condition.

The second step consists of a sufficiency analysis for the following four models. Equations (1) and (2) correspond to Model I. in relation to the outcome's presence or absence, and Equations (3) and (4) correspond to Model II. in relation to the outcome's presence or absence:

$$
\begin{gathered}
\text { CSP }=\mathrm{f}(\mathrm{GRI}, \text { ReportEvent, ReportGRI, fs_noyears, fs_noreports, fs_rev, fs_eps, fs_per) } \\
\sim \mathrm{CSP}=\mathrm{f}(\mathrm{GRI}, \text { ReportEvent, ReportGRI, fs_noyears, fs_noreports, fs_rev, fs_eps, fs_per) } \\
\mathrm{CSP}=\mathrm{f}(\mathrm{GRI}, \text { ReportEvent, ReportGRI, fs_noyears, fs_noreports, fs_revvar, fs_epsvar, fs_pervar) } \\
\sim \mathrm{CSP}=\mathrm{f}(\mathrm{GRI}, \text { ReportEvent, ReportGRI, fs_noyears, fs_noreports, fs_revvar, fs_epsvar, fs_pervar) }
\end{gathered}
$$

The estimation software is fsQCA 3.0 [109].

\section{Results and Discussion}

This section presents the results of the fsQCA regarding the necessary and sufficient conditions for the outcome of exclusion from or inclusion in the SRI index. The main findings and implications are discussed.

\subsection{Necessity Analysis}

Table 6 shows the results of the necessity analysis for the all the conditions included in the two alternative models specified.

A condition is necessary when its consistency value is above $0.9[79,80,110]$; coverage scores are provided for completeness, but no criterion exists for determining the necessity of a condition. The negation rows (shown with a " $\sim$ " preceding the condition code) present the respective logical negation of the identified conditions. No necessary conditions exist for either the presence of the outcome (CSP) or the absence of the outcome ( CSP); that is, no condition is present every time the outcome is present. Therefore, no unique condition is necessary to explain neither the exclusion from nor the inclusion in the S\&P $500 \mathrm{E} \& S$ index and, by extension, a good or poor CSP.

\subsection{Sufficiency Analysis}

This section presents the analysis of sufficient conditions. As this is a first exploratory study, we set a frequency cut-off of only one case for a combination of causal conditions to be considered in the analysis. The estimation of the four models presented in Section 3.5 (Equations (1)-(4)) yields a solution consistency value above 0.75 , which is usually the minimum acceptable value [79]. Tables 7-10 show the results of the fsQCA complex solution for Models I. and II., comprising different paths that lead to a good CSP, which motivates inclusion in the S\&P 500 E\&S index (Table 7; Table 9) or to a poor CSP, which motivates exclusion from the index (Table 8; Table 10). Table 7; Table 8 show the results for Model I. (considering CFP static measures) and Table 9; Table 10 show the results for Model II. (dynamic CFP measures). Consistency (of the entire solution and of each individual path) indicates the extent to which a causal combination leads to the inclusion in or exclusion from the index, and coverage 
represents how much of the outcome (inclusion or exclusion) is explained by each path and by the solution as a whole [92]. Raw coverage is the percentage of events displaying both the specific event type (exclusion or inclusion, that is, CSP and CSP) and the specific path; as the same events can display various paths, unique coverage shows the percentage of events covered by that single path and no other $[79,84]$.

Table 6. Necessity analysis.

\begin{tabular}{|c|c|c|c|c|}
\hline \multirow[b]{2}{*}{ Conditions } & \multicolumn{2}{|c|}{ CSP (Inclusion) } & \multicolumn{2}{|c|}{ CSP (Exclusion) } \\
\hline & Consistency & Coverage & Consistency & Coverage \\
\hline GRI & 0.876923 & 0.575758 & 0.688525 & 0.424242 \\
\hline$\sim$ GRI & 0.123077 & 0.296296 & 0.311475 & 0.703704 \\
\hline ReportEvent & 0.630769 & 0.621212 & 0.409836 & 0.378788 \\
\hline$\sim$ ReportEvent & 0.369231 & 0.4 & 0.590164 & 0.6 \\
\hline ReportGRI & 0.415385 & 0.72973 & 0.163934 & 0.27027 \\
\hline ReportGRI & 0.584615 & 0.426966 & 0.836066 & 0.573034 \\
\hline fs_noyears & 0.394769 & 0.52755 & 0.376721 & 0.472451 \\
\hline fs_noyears & 0.605231 & 0.508532 & 0.623279 & 0.491469 \\
\hline fs_noreports & 0.564461 & 0.613956 & 0.378197 & 0.386044 \\
\hline$\sim \mathrm{fs} \_$noreports & 0.435538 & 0.427385 & 0.621803 & 0.572615 \\
\hline fs_rev & 0.414308 & 0.52444 & 0.400328 & 0.47556 \\
\hline$\sim$ fs_rev & 0.585692 & 0.50998 & 0.599672 & 0.49002 \\
\hline fs_eps & 0.437692 & 0.49651 & 0.472951 & 0.50349 \\
\hline$\sim$ fs_eps & 0.562308 & 0.532023 & 0.527049 & 0.467977 \\
\hline fs_per & 0.418 & 0.497984 & 0.449016 & 0.502016 \\
\hline$\sim$ fs_per & 0.582 & 0.529535 & 0.550984 & 0.470465 \\
\hline fs_revvar & 0.475385 & 0.493768 & 0.519344 & 0.506232 \\
\hline$\sim$ fs_revvar & 0.524615 & 0.537685 & 0.480656 & 0.462315 \\
\hline fs_epsvar & 0.444462 & 0.494946 & 0.483279 & 0.505054 \\
\hline$\sim$ fs_epsvar & 0.555538 & 0.533935 & 0.516721 & 0.466065 \\
\hline fs_pervar & 0.477846 & 0.536535 & 0.439836 & 0.463465 \\
\hline$\sim$ fs_pervar & 0.522154 & 0.498312 & 0.560164 & 0.501688 \\
\hline
\end{tabular}

"fs" represents a calibrated condition; " $\sim$ " represents absence of the condition or outcome; "CSP" represents corporate sustainability performance, with presence corresponding to an inclusion event in the S\&P 500 E\&S index (good CSP), and absence corresponding to an exclusion event (poor CSP); "GRI" represents inclusion in the GRI SD database; "ReportEvent" indicates whether the company published a report in the event year; "ReportGRI" indicates whether the report follows the GRI standards; "noyears" indicates the number of years between the event year and the previous exclusion or inclusion; "noreports" indicates the number of reports included in the GRI SD database; "rev" stands for the revenue figure in the event year; "eps" is the EPS in the event year; "per" is the PER in the event year; "revvar", "epsvar" and "pervar" stand respectively for the change in the corresponding figures between the event year and the year of the previous exclusion or inclusion.

Table 7. Sufficiency Analysis. Model I-Presence: CSP (inclusion).

\begin{tabular}{|c|c|c|c|c|}
\hline Path & Combination & Raw Coverage & Unique Coverage & Consistency \\
\hline 1 & $\begin{array}{l}\text { GRI*ReportEvent }{ }^{*} \text { ReportGRI* } \\
\text { fs_noyears }{ }^{*} \mathrm{fs} \_ \text {noreports* }{ }^{*} \text { fs_rev }{ }^{*} \sim \mathrm{fs} \_ \text {per }\end{array}$ & 0.0746154 & 0.00492308 & 0.911654 \\
\hline 2 & $\begin{array}{l}\text { GRI*ReportEvent }{ }^{*} \text { ReportGRI* } \\
\text { fs_noyears }^{*}{ }^{*} \text { s_noreports* }{ }^{*} \text { fs_eps }{ }^{*} \sim \text { fs_per }\end{array}$ & 0.084 & 0.0109231 & 0.845201 \\
\hline 3 & $\begin{array}{l}\text { GRI*ReportEvent }{ }^{*} \text { ReportGRI* } \\
\text { fs_noyears }{ }^{*} \text { fs_noreports }{ }^{*} f_{s} \text { rev }{ }^{*} \text { fs_eps }\end{array}$ & 0.0721538 & 0.00492309 & 0.901923 \\
\hline 4 & $\begin{array}{l}\text { GRI*ReportEvent }{ }^{*} \text { ReportGRI } \sim \text { fs_noyears* } \\
\text { fs_noreports* } \sim \text { fs_rev } \sim \text { fs_eps } \sim \text { fs_per }\end{array}$ & 0.107692 & 0.0607692 & 0.77348 \\
\hline 5 & 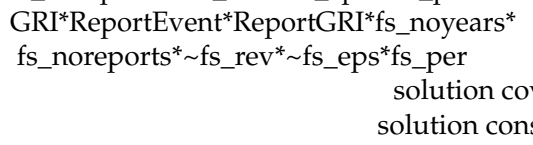 & $\begin{array}{l}0.0783077 \\
\text { overage: } 0.187846 \\
\text { nsistency: } 0.804348\end{array}$ & 0.0295385 & 0.852596 \\
\hline
\end{tabular}

"fs" represents a calibrated condition; " $\sim$ " represents absence of the condition; "** is logic operator AND; "CSP" represents an inclusion event in the S\&P 500 E\&S index; "GRI" represents inclusion in the GRI SD database; "ReportEvent" indicates if the company published a report in the event year; "ReportGRI" indicates if the report follows the GRI standards; "noyears" indicates the number of years between the event year and the previous exit or entry; "noreports" indicates the number of reports included in the GRI SD database; "rev" stands for the revenue figure in the event year; "eps" is the EPS in the event year; "per" is the PER in the event year; frequency cut-off: 1; consistency cut-off: 0.77348 . 
Table 8. Sufficiency Analysis. Model I-Absence: CSP (exclusion).

\begin{tabular}{|c|c|c|c|c|}
\hline Path & Combination & Raw Coverage & Unique Coverage & Consistency \\
\hline 1 & $\begin{array}{l}\sim \mathrm{GRI}^{*} \sim \text { ReportEvent }{ }^{*} \sim \text { ReportGRI } \sim \text { fs } \\
\text { _noyears }{ }^{*} \sim \mathrm{fs} \_ \text {noreports* } \sim \text { fs_rev }{ }^{*} \mathrm{fs} \_ \text {eps }{ }^{*} \mathrm{fs} \_ \text {per }\end{array}$ & 0.0621311 & 0.0314754 & 0.768763 \\
\hline 2 & 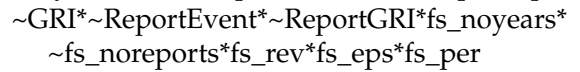 & 0.0485246 & 0.0178689 & 0.760926 \\
\hline \multicolumn{5}{|c|}{$\begin{array}{l}\text { solution coverage: } 0.08 \\
\text { solution consistency: } 0.792208\end{array}$} \\
\hline
\end{tabular}

"f "represents a calibrated condition; " " represents absence of the condition; "*" is the logic operator AND; "CSP" represents an inclusion in the S\&P 500 E\&S index; "GRI" represents inclusion in the GRI SD database; "ReportEvent" indicates whether the company published a report in the event year; "ReportGRI" indicates whether the report follows the GRI standards; "noyears" indicates the number of years between the event year and the previous exclusion or inclusion; "noreports" indicates the number of reports included in the GRI SD database; "rev" stands for the revenue figure in the event year; "eps" is the EPS in the event year; "per" is the PER in the event year; frequency cut-off: 1 ; consistency cut-off: 0.760926 .

Table 9. Sufficiency Analysis. Model II-Presence: CSP (inclusion).

\begin{tabular}{|c|c|c|c|c|}
\hline Path & Combination & Raw Coverage & Unique Coverage & Consistency \\
\hline 1 & $\begin{array}{l}\text { GRI*ReportEvent*ReportGRI* }{ }^{*} \sim \text { fs_noyears } \\
\text { fs_noreports* } \sim \text { fs_epsvar } \sim \text { fs_pervar }\end{array}$ & 0.141077 & 0.0873846 & 0.764804 \\
\hline 2 & $\begin{array}{l}\text { GRI*ReportEvent*ReportGRI*fs_noyears* } \\
\text { fs_noreports }{ }^{*} \text { fs_epsvar* }{ }^{*} \sim \text { fs_pervar }\end{array}$ & 0.0795385 & 0.0166154 & 0.848933 \\
\hline 3 & $\begin{array}{l}\text { GRI*ReportEvent**ReportGRI*fs_noyears* } \\
\text { fs_noreports } * \text { fs_epsvar }{ }^{*} \text { fs_pervar }\end{array}$ & 0.107231 & 0.0470769 & 0.882278 \\
\hline \multicolumn{5}{|c|}{$\begin{array}{l}\text { solution coverage: } 0.216308 \\
\text { solution consistency: } 0.790332\end{array}$} \\
\hline
\end{tabular}

"fs" represents a calibrated condition; " " represents absence of the condition; "*" is logic operator AND; "CSP" represents an inclusion in the S\&P 500 E\&S index; "GRI" represents inclusion in the GRI SD database; "ReportEvent" indicates whether the company published a report in the event year; "ReportGRI" indicates whether the report follows the GRI standards; "noyears" indicates the number of years between the event year and the previous exclusion or inclusion; "noreports" indicates the number of reports included in the GRI SD database; "epsvar" and "pervar" stands respectively for the change in the corresponding figures between the event year and the year of the previous exclusion or inclusion; frequency cut-off: 1 ; consistency cut-off: 0.755935.

Table 10. Sufficiency Analysis. Model II-Absence: CSP (exclusion).

\begin{tabular}{|c|c|c|c|c|}
\hline Path & Combination & Raw Coverage & Unique Coverage & Consistency \\
\hline 1 & $\begin{array}{l}\sim \mathrm{GRI}^{*} \sim \text { ReportEvent*} \sim \text { ReportGRI*fs_noyears** } \\
\text { fs_noreports* } \sim \text { fs_revenuevar* } \sim \text { fs_epsvar }{ }^{*} \sim \mathrm{fs} \_ \text {pervar }\end{array}$ & 0.0521311 & 0.0162295 & 0.75 \\
\hline \multirow[t]{2}{*}{2} & 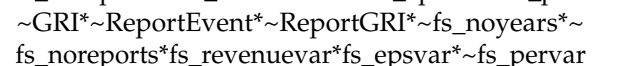 & 0.0896721 & 0.0537705 & 0.762901 \\
\hline & $\begin{array}{r}\text { solution covera } \\
\text { solution consiste }\end{array}$ & $\begin{array}{l}\text { age: } 0.105902 \\
\text { ency: } 0.769048\end{array}$ & & \\
\hline
\end{tabular}

"fs" represents a calibrated condition; " $"$ " represents absence of the condition; "** is logic operator AND; "CSP" represents an inclusion in the S\&P 500 E\&S index; "GRI" represents inclusion in the GRI SD database; "ReportEvent" indicates whether the company published a report in the event year; "ReportGRI" indicates whether the report follows the GRI standards; "noyears" indicates the number of years between the event year and the previous exclusion or inclusion; "noreports" indicates the number of reports included in the GRI SD database; "revvar", "epsvar" and "pervar" stands respectively for the change in the corresponding figures between the event year and the year of the previous exclusion or inclusion; frequency cut-off: 1; consistency cut-off: 0.75 .

The fsQCA complex solution shows five different paths related to the inclusion in the S\&P 500 E\&S and based on CSD and CFP static measures (Table 7). All the paths include high levels of the four CSD causal conditions, and all except Path 4. include a high number of years elapsed between the inclusion year and the year of the previous exclusion. Therefore, in a high number of cases, a long period of exclusion favours inclusion in the index. Regarding the static CFP measures, there is one path (Path 4.) that shows low levels for all the three CFP measures considered in Model I. specification and a shorter period of exclusion. This path reveals that companies with a high commitment to CSD are included in the index despite a poor CFP. We could argue that cases included in Path 4 . are companies that have rapidly reacted to the previous exclusion event by making an extraordinary financial effort to improve 
their CSP and return to the index, in line with Slager [84], and that are trying to properly communicate that effort through a high commitment to CSD. The rest of paths show different combinations of high and low CFP static measures. Paths 1. to 3. reveal some support to the slack resources theory, as they include high levels of at least one accounting-based CFP measure (revenue for Path 1., EPS in Path 2., and revenue and EPS in Path 3.), but they are contradicted by Paths 4. and 5. showing that low levels of revenue and EPS can also be present when a company is included in the index. Path 5. corresponds to companies that have been included in the index after a long exclusion period, and that exhibit a good CSD, a poor CFP based on accounting measures and a high PER. This could be indicative of a market capitalization effect leading to a "technical" inclusion in the index not directly derived from an improved CSP. The PER ratio shows low levels in Paths 1. and 2., and is not relevant in Path 3., indicating that companies included in the index and exhibiting a high CSD and a high CFP based on accounting measures, are not rewarded by the stock market with a higher stock price.

Exclusions are explained by two alternative paths considering CSD and static CFP measures as causal conditions (Table 8). The two paths show low levels of CSD, accompanied in Path 2. by high levels of CFP regarding the three static measures included in Model I. This second path is the mirror opposite of Path 4., leading to inclusions (Table 7), and shows that companies not committed with CSD are excluded from the index despite having a strong CFP and a long inclusion period. Path 1 . is related to companies that had been included in the index for a short period before the exclusion event and show a poor CSD together with low revenue and high EPS and PER. A high PER is present in the two paths, suggesting that the stock market does not penalise companies with a poor CSP.

Moving to Model II., based on dynamic measures of CFP (variations in revenue, EPS and PER), three alternative paths lead to inclusions (Table 9). Once again, all the paths include high levels of CSD. The variation in revenue is not relevant in any of these paths. Path 1 . shows that companies included in the index after a short exclusion period have experienced a decrease in their CFP, perhaps due to a great financial effort to improve CSP and return to the index in line with Slager [84]. Paths 2. and 3. alternatively show a decrease in EPS and increase in PER, and an increase in EPS and decrease in PER with a high CSD and a long time of exclusion previous to the inclusion. The three paths reflect that companies with a high commitment to CSD are included in the index, despite a deterioration of some measures of CFP.

Table 10 shows two paths leading to exclusions combining CSD and dynamic measures of CFP as causal conditions. Variation in revenue appears in the two paths, and both are associated with low levels of CSD. Path 1. shows that companies with a low commitment to CSD and with larger periods of presence in the index before the exclusion event, have experienced a decrease in their CFP. Path 2. shows that companies with a poor CSD and a low inclusion period have been excluded, despite an increase in revenue and EPS. This second path also shows an increase in PER that could be motivated by the decrease in EPS.

These results allow us to obtain the first straightforward conclusion: Proposition 4. (equifinality) is confirmed in the four model specifications, as we can see that different configurations or paths explain the same outcome. Inclusions in the S\&P 500 E\&S index are explained by five paths under Model I. specification (static CFP) and three paths under Model II. (variations in CFP); exclusions from the S\&P 500 E\&S index are explained by two different paths both in Model I. and Model II.

In a similar vein, the results evidence the existence of complexity (Proposition 5.). Both the necessity and the sufficiency analyses reveal that there is no single condition related in a univocal manner to a specific outcome (inclusion or exclusion) neither in Model I. nor in Model II., that is, the effect of each condition depends on others.

Regarding Proposition 6. (causal asymmetry), the results validate this proposition for Model II., where the paths leading to exclusions are not just the mirror opposite to any of the paths leading to inclusions; however, Model I. shows an exception, as Path 4. leading to the inclusion in the S\&P 500 E\&S is exactly the mirror opposite of Path 2. related to the exclusion. 
Furthermore, the specific conditions considered to measuring CSD and CFP show additional interesting results. First, we can conclude that a combination of CSD measures are a necessary precondition for the outcome to take place (either inclusions or exclusions): All the paths leading to the inclusion in the S\&P $500 \mathrm{E} \& S$ index include the presence of high levels of the four CSD measures, while all the paths leading to the exclusion from the index show the absence of the four CSD measures. Therefore, for this combination of CSD causal conditions, Proposition 6. is rejected because there is no causal asymmetry. Proposition 7. (asymmetry) is also rejected in relation to CSD measures, because high levels of CSD are always related to inclusions and low levels of CSD are always related to exclusions. These results could be interpreted as a confirmation of Propositions $2 \mathrm{a}$. and $2 \mathrm{~b}$. In any case, these four CSD antecedents are not sufficient in the four model specifications as they do not lead to the outcome by themselves, but need the concurrence of different CFP conditions.

A high commitment to CSD would be expected to lead to a high CSP, while a subsequent inclusion in the S\&P 500 E\&S index would demand high levels of static CFP measures (Model I.). In the same vein, a low or no commitment to CSD leading to an exclusion would be associated with low static CFP measures. However, neither Paths 1. to 5 . in Table 7 nor Paths 1. to 3. in Table 8 point clearly in this direction, as different paths indistinctly include both high and low levels of the same CFP measures. More strikingly, Path 4 . shows that low levels of the three static CFP measures considered (revenue, EPS and PER) lead to the inclusion in the index, while Path 2. shows that high levels of the three measures lead to the exclusion. These paths openly contradict Propositions $1 \mathrm{a}$. and $1 \mathrm{~b}$., and are an exception to Proposition 6. of causal asymmetry. Therefore, when a company shows a poor CSD, it is delisted from the index even if its CFP is strong, and when a company shows a good CSD it is included in the index despite having a low CSP. The results do not support the idea that a good CSD should be accompanied by at least one strong CFP measure to lead to an inclusion after a previous exclusion, because Path 4 . in Table 7 shows that a good CSD together with low levels of all the three CFP measures can explain inclusions. The results also confirm Proposition 7. (asymmetry) because all the static CFP measures individually contribute to inclusions and exclusions in Model I. Specifically, the results confirm that high levels of CFP contribute to both inclusions and exclusions. In relation to exclusions, high levels of EPS and PER are present in the two paths leading to exclusions. In particular, the role of PER is interesting because this study suggested that exclusions could be motivated by decreases in companies' market capitalization, which would cause a "technical" delisting and not a delisting motivated by a negative change in CSP. Finding high PER levels associated with exclusions reinforces the validity of inclusions and exclusions as proxies for CSP. It is also worth mentioning that we could expect a negative relationship between PER and EPS in the different paths, because a high EPS could cause a low PER if the stock price does not capture improvements on future cash flows. Pathways 2. and 5. related to inclusions (Table 7) show this interrelation, but it is neither present in Path 4. leading to inclusions nor in the two paths leading to exclusions. Regarding the different behaviour of accounting-based or market-based CFP measures, Paths 1 . to 3. seem to support a positive relation between accounting CFP measures and inclusions in line with the slack resources theory, although this is contradicted by Paths 4 . and 5. The results for the PER ratio in many paths show low PER related to inclusions and high PER related to exclusions. These results partially support previous evidence by event studies regarding the lack of a relevant effect of inclusions in SRI indices on stock prices, but contradict previous results of negative stock price reactions to exclusions. These results also contradict the accepted idea that a high capacity of market-based CFP measures can better capture the positive influence of a good CSP. This idea is in line with Endrikat et al. [14], who found a stronger relationship between accounting-based CFP measures and CSP, than between market-based CFP measures and CSP.

Next, we focus on Model II., on the dynamic measures of CFP (variations in revenue, EPS and PER between the event year and that of the previous entry or exit). We expected high CSD levels leading to inclusions in the index to be accompanied by an improvement in CFP, and low CSD levels leading to exclusions to combine with a deterioration of CFP. We again find mixed evidence of the impact of CFP 
change on inclusions (Table 9). On the other hand, Proposition 6. (causal asymmetry) is confirmed, because no path leading to exclusions is the mirror opposite of paths leading to inclusions. Regarding Proposition 7. (asymmetry in the effects of the conditions on the outcome), it is only confirmed for variations (either increases or decreases) in EPS and for decreases in PER, as they are related both to inclusions and exclusions. PER increases are only related to inclusions. It is noticeable that the variation in revenue does not appear in any of these paths. This is interpreted as a sign of irrelevance of this specific condition when considering the other ones. The results do not support Proposition 3a., because inclusions are not clearly associated with an improved CFP, and Path 1 . in Table 9 openly contradicts this idea, because the companies included display a decrease of both EPS and PER. Proposition 3b. is supported by Path 1. in Table 10, showing that exclusions are related to decreases in the three dynamic CFP measures. Furthermore, a decrease in PER is present in the two paths leading to poor CSP (exclusions). This is consistent with the positive CFP-CSP link extensively supported by previous research. More interestingly, the rejection of Proposition 3a. and partial confirmation of Proposition 3 b. support the idea that CSI has stronger effects than CSR $[28,29]$, that is, that financial markets are more sensitive to a deterioration of CSP or to irresponsible corporate behaviours than to good CSP. Finally, large exclusion periods are associated with a high number of paths leading to inclusions both in Model I. and Model II. (only Path 4. in Table 7 and Path 1. in Table 9 show a low exclusion period related to an inclusion in the index). This result could indicate that companies that have been excluded from the index need a long period to improve their CSP and return to the index.

In summary, the results fully confirm Propositions 2a., 2b., 4. and 5., whereas Propositions 3b., 6 ., 7. receive partial support and Propositions 1a., 1b. and 3a. are rejected. Regarding Propositions 1a. and 1b., results in Tables 7 and 8 reveal only limited evidence of a high CFP unambiguously linked to a good CSP, and a low CFP related to a poor CSP. In fact, two of the alternative configurations leading to inclusions in or exclusions from the index clearly contradict these ideas (Path 4 . in Table 7 and Path 2. in Table 8). On the other hand, Propositions $2 \mathrm{a}$. and $2 \mathrm{~b}$. are fully confirmed because the fsQCA results show that the four CSD causal conditions are necessary (but not sufficient) to lead to the outcome: High CSD is always related to good CSP (inclusions), and low CSD is always related to poor CSP (exclusions); however, all the paths also include different combinations of the remaining causal conditions. This positive relation between CSD and CSP is consistent with previous research [12,13]. Proposition 3a. (Table 9) is also clearly contradicted by Path 1., and ambiguously supported by Paths 2. and 3. because different inclusion events show decreases in all, or at least one, of the relevant CFP measures (variation in EPS and PER). By contrast, Proposition 3b. is clearly supported by Path 1. of Table 10, showing that low or no CSD together with a decrease in CFP measures are antecedents of an exclusion from the index. Proposition 4. (equifinality) is confirmed by the alternative pathways to inclusions and exclusions under the four alternative model specifications, and Proposition 5. (complexity) is confirmed, because no single condition in isolation explains the outcome, and a condition's impact depends on the presence or absence of other causal conditions. Proposition 6. (causal asymmetry) is confirmed by Model II., but has an exception in Model I., where two pathways leading to inclusions and exclusions are the mirror opposite of one another. Finally, Proposition 7. (asymmetry) is partially confirmed. In general, all the causal conditions are both present and absent in the determination of both the presence and absence of the outcome; however, a closer look shows that, in some cases, a specific state of the antecedent is only related to an specific state of the outcome (for example, an increase in PER or a low PER are only related to inclusions).

The small sample size of this study has allowed a case-oriented interpretation of the results, based on the direct observation and knowledge of the particularities of each set of cases. Robustness tests are generally recommended for larger sample sizes [111], and there is no general agreement on how to perform them. They are frequently conducted through changes in the calibration of the variables. This study has tested two alternative model specifications looking for any difference between static and dynamic CFP measures in leading to CSP. The low coverages obtained are derived from the small-N dataset, and confirm a highly heterogeneous sample and the difficulty of searching 
for any straightforward relation between CFP and CSP. Dynamic measures of Model II. slightly improve the solution coverage, and show a specific set of cases clearly supporting Proposition $3 \mathrm{~b}$. Some of the variables included in both Model I. and Model II. have not needed any calibration at all, while calibrated ones (those related with both static and dynamic financial performance, together with the number of sustainability reports and the time elapsed between an entry and exit event) cannot be reasonably recalibrated applying any sound alternative argument. As we acknowledge in the limitations subsection, it would be more interesting to explore alternative model specifications, considering other financial performance measures or even other relevant dimensions of corporate performance, than testing alternative calibrations of continuous variables. This could be addressed in future research.

\section{Conclusions, Implications and Limitations}

This study makes several theoretical and practical contributions with implications for both researchers and private and public decision-makers. In particular, we highlight three outstanding contributions in three underdeveloped research areas: The application of the fsQCA to the analysis of the CFP-CSD-CSP links, the analysis of the preconditions of inclusions in and exclusions from SRI indices, and the focus on the role of CSD as an antecedent of CSP. Limitations are also acknowledged.

\subsection{Theoretical Contributions}

Several decades of research dealing with the business case of sustainability have explored different causal relationships between CSP and CFP, considered multiple mediating and moderating factors and yielding heterogeneous conclusions. This study has approached the analysis of the relationship between CFP and CSP from an alternative perspective to most previous literature on this issue. Facing the inconclusive results of previous extensive research on the CFP-CSD-CSP links, and accounting for the signals of equifinality, complexity and asymmetry revealed by some studies, we have attended the call for applying new research methodologies into this field [18]. QCA is a particularly suitable analytical framework to deal with these features, and it has been used by some incipient literature to analyse inconsistent complex results of previous studies [17], and to contrast its results with traditional empirical methods [89].

Rather than exploring the direct link between CFP and CSP, this study applies fsQCA to clarify the complex and asymmetrical links between them. In contrast to previous literature, CFP is not considered a dependent variable but as an antecedent together with CSD, while CSP (considering inclusions in and exclusions from a SRI index as proxy) is considered an outcome to be explained. Little previous research has been done examining the preconditions or antecedents of additions to and deletions from SRI indices (Ziegler and Schröder [10] are an exception). The influence of CSD on CSP has also received little attention. Furthermore, CSP, CFP or CSD could be moderating or mediating factors of one another, as CFP and CSP can have an influence on CSD intensity and quality and CSD can have an influence on CFP and CSP. Although the fsQCA technique does not allow for the examination of mediating models, nor to include control variables [91], it provides valuable information regarding how causal conditions interact to produce a specific outcome.

An important novelty and contribution of this study to the incipient application of the fsQCA in the CFP-CSP research field is that the outcome is defined in a dual manner. This approach enables measuring a high level (presence) and low level (absence) of the outcome (good or poor CSP) while analysing two separate but complementary constructs: Inclusions in a SRI index (proxy for a good CSR) and exclusions from a SRI index (proxy for a poor CSP).

Another particular contribution of this study is considering inclusions as proxies for good CSP, and exclusions as proxies for poor CSP (similar to [4]), in contrast to previous literature, which has mainly focused on being listed or not as proxies for CSP. Furthermore, a different approach is used on the analysis of these exclusions and inclusions events by only focusing on those preceded by exclusions from or inclusions in the SRI index. This approach advances the proposal by Eom 
and Nam [68], who simply distinguish between the time of the index introduction and those of its subsequent revisions.

The results reveal that no single CFP indicator explains the exclusion from or inclusion in an SRI index, and that high CSD (measured through four complementary indicators) is a necessary but not sufficient antecedent of good CSP (inclusion in an SRI index) and low CSD is a necessary but not sufficient condition for poor CSP (exclusions). We have found complexity in the relationship between CFP and CSP, as the impact of each CFP measure depends on other financial or non-financial causal conditions. The study also identifies alternative paths or combinations of causal conditions to reach the same outcome. Some of these paths provide some support to the slack resources theory as they show that high CSP and CSD are related to an improvement in CFP and that low CSP and CSD are related to a decrease in CFP (fewer resources available to CSP and CSD). However, the analysis identifies specific paths directly contradicting our expectations of improved CFP associated with good CSP and of a low CFP related to a poor CSP. Furthermore, the results provide some evidence of a stronger relation between CSP and accounting-based CFP measures than with market-based ones, in contrast to most literature findings and in line with Endrikat et al. [14].

\subsection{Implications for Researchers}

This study has demonstrated that fsQCA is a valuable alternative and/or complementary methodological approach. FsQCA is particularly useful for regression analyses that consider being listed in a SRI index as proxy for CSP and for event studies that analyse the impact of inclusions in and exclusions from an SRI on CFP. The confirmation of equifinality, complexity and asymmetry for many of the causal conditions both individually and in combination, particularly for CFP measures, indicates that the raw application of statistical techniques to analyse the CFP-CSP links can be misleading. In particular, the effects of high and low CFP on both high and low CSP are complex and depend on other causal conditions. Therefore, we support a redirection of the CFP-CSP research towards case-oriented research exploring the circumstances under which CSR contributes to competitiveness [18,40]. Research should consider the influence of good or bad management [17], because this study has shown that the search of a univocal and unidirectional relationship between CFP and CSP is not justified. We encourage future research using fsQCA both in isolation as well as in conjunction with other methodologies to advance knowledge in the CFP-CSP research field.

Future research could also incorporate these study's results to improve our understanding of the CSP-CSD-CFP interrelations. We have evidenced the necessity (though not sufficiency) of CSD for a company to be included in an SRI index as a consequence, presumably, of a better CSP. The influence of CSD on CSP remains under explored; in particular, their relationship in the context of SRI indices requires further analysis. Slager [84], for instance, uses a fsQCA to identify the antecedents of the efforts of companies included in the FTSE4Good index to improve their CSP in order to remain included, but does not consider CSD among those antecedents.

New contributions could analyse other relevant antecedents of CSD, such as corporate governance or board structure indicators, which have been extensively related to CSD in prior research. Model I. in this study has included sales as proxy of company size and EPS and PER as measures of profitability, revealing mixed interactions with CSD indicators to produce a better or poorer CSP. Alternative measures could be tested in future research.

\subsection{Implications for Private and Public Decision-Makers}

The empirical results clearly support the importance of CSD, because its absence impedes a high CSP and the subsequent inclusion in an SRI index. This result highlights the need to reinforce both the regulatory frameworks demanding greater transparency on non-financial issues and the initiatives working on standardization to improve the quality of CSD. US policymakers should acknowledge the powerful incentives of being subjected to a higher scrutiny on non-financial issues in order to improve CSP, as the European Union has already done. CSD should also expand among small 
and medium-sized companies in countries with mandatory non-financial reporting already in place, and among larger ones, particularly in the Southeast of the European Union [48,49].

Our results also have direct implications for companies willing to gain recognition for their CSP through the inclusion in an SRI index, suggesting the necessity of a higher commitment to CSD. CSD based on the publication of reports following the GRI or IR guidelines enables companies to be assessed under a globally accepted standard. Even those companies that have experienced a deterioration of their CSP could benefit from a well-oriented and focused CSD to avoid the negative impacts on market value that this study's results have partially supported. Furthermore, an increase in commitment to CSD could lead to an improvement of CSP due to the higher scrutiny and pressure of stakeholders.

We have found some evidence of the long period required to solve CSP deficiencies in companies that had been excluded from the S\&P 500 E\&S index before returning to the index, as well as mixed or ambiguous associations with CFP measures. Therefore, business managers should also acknowledge the importance of a strategic integration and planning of CSR in order to achieve meaningful CSP improvements in short periods together with CFP improvements.

Finally, CSR rating agencies and SRI indices managers should devote bigger efforts to improving and guaranteeing the quality and accuracy of their CSP rating methodologies. Similarly to Eom and Nam [68], we acknowledge that the absence of a clear and direct relationship between CFP and CSP can be a sign of the inability of SRI indices to properly capture companies' CSP. We have also pointed out the possibility of investors' mixed perceptions about the financial implications of good or poor CSP (Eom and Nam [68] talk about pessimistic and optimistic investors). This leads again to the need for an increase in CSD, so that the potential financial benefits derived from CSR are properly understood by financial markets. CSD could also contribute to closing the gap between the supply and demand of SRI products. This also demands a high policy commitment to expand SRI and contribute to the integration of CSR matters into investment decisions. Integrated and joint actions are needed from governmental and non-governmental institutions, as well as from CSR rating agencies and companies themselves, to break the irrelevance of CSD in market valuations found in previous research. This is not an easy task because sustainability information is not easily verifiable regardless of the adoption of any of the current available reporting standards. Companies should design effective CSD frameworks, focused not only on reporting but also on permanent dialog and interaction with their stakeholders.

\subsection{Research Limitations}

This study has some limitations. Regarding the fsQCA technique, as Cuadrado-Ballesteros et al. [85] note, each model specification in a fsQCA should include a limited number of factors because the higher the number of antecedents considered, the higher the number of possible paths leading to a same outcome, which reduces valid inference. Logically, there are more factors with a possible influence on CSP and on changes in SRI indices' composition; similarly, CFP can be approached using alternative measures. Different model specifications could also be tested considering CFP or CSD as outcomes instead of antecedents. All these are open avenues for future research applying fsQCA alone or in combination with other techniques. Future research could replicate and further develop this analysis over other SRI indices and other stock markets different from the US market.

An important limitation is the use of the GRI SD database to verify whether the sample companies had published a sustainability report, as Northern America shows lower GRI adoption levels [52,106]. Following Goettsche et al. [62], we also acknowledge that there is a remote possibility that some companies issuing sustainability reports (either GRI-aligned or not) may not appear in the GRI SD database. An alternative and more time-consuming and effort-demanding procedure, followed by Schreck and Raithel [65], would be to explore the companies' websites or even directly contacting them to confirm the availability of sustainability reports for the year previous to the inclusion or exclusion event.

Finally, we focus again on the debate surrounding the validity of inclusions and exclusions from an SRI index as proxies for CSP [10]. This study supports these inclusion and exclusion events as accurate 
measures of CSP. However, the rather obscure rating methodologies supporting SRI indices undermine their credibility and make it difficult to discern whether inclusions in or exclusions from SRI indices are really directly derived from a good or poor CSP. Thus, future research could focus on analysing inclusions and exclusions as independent constructs from CSP in order to gain a deeper understanding on the effects of CSP on them, either using aggregated measures or, preferably, decomposing it into specific ESG issues. Being included in an SRI index could be considered as an antecedent of CSP. In fact, Searcy and Elkhawas [11] explain the benefits derived from being listed in a SRI index (e.g., using the index logo at their websites and in corporate reports) so that companies could find incentives to try to improve their CSP in order to be included or remain in the index [84].

In summary, this study derives some relevant implications for researchers, business managers and policymakers. Research on the CFP-CSP link, with its long past trajectory and its present controversial state, still has a long future ahead.

Author Contributions: Conceptualization and Data collection J.P.-C. and N.R.-C.; Methodology, Software and Formal Analysis, N.R.-C. and M.V.-G; All authors contributed to Writing-Original Draft Preparation and Writing-Review \& Editing. All authors have read and approved the manuscript.

Funding: This research received no external funding.

Acknowledgments: The authors are grateful to the two anonymous reviewers for their feedback and helpful and valuable comments on a previous version of this article.

Conflicts of Interest: The authors declare no conflict of interest.

\section{Abbreviations}

$\begin{array}{ll}\text { CFP } & \text { corporate financial performance } \\ \text { CSD } & \text { corporate sustainability disclosure } \\ \text { CSI } & \text { corporate social irresponsibility } \\ \text { CSP } & \text { corporate sustainability performance } \\ \text { CSR } & \text { corporate social responsibility } \\ \text { ESG } & \text { environmental, social and governance } \\ \text { FsQCA } & \text { fuzzy-set qualitative comparative analysis } \\ \text { GRI SD database } & \text { GRI sustainability disclosure database } \\ \text { GRI } & \text { Global Reporting Initiative } \\ \text { IR } & \text { integrated reporting } \\ \text { QCA } & \text { qualitative comparative analysis } \\ \text { ROA } & \text { return on assets } \\ \text { ROE } & \text { return on equity } \\ \text { S\&P 500 ESG } & \text { S\&P 500 ESG Factor Weighted Index } \\ \text { S\&P 500 E\&S } & \text { S\&P 500 Environmental and Socially Responsible Index } \\ \text { SRI } & \text { socially responsible investment }\end{array}$

\section{References}

1. Rezaee, Z. Business Sustainability Research: A Theoretical and Integrated Perspective. J. Account. Lit. 2016, 36, 48-64. [CrossRef]

2. Brooks, C.; Oikonomou, I. The Effects of Environmental, Social and Governance Disclosures and Performance on Firm Value: A Review of the Literature in Accounting and Finance. Brit. Account. Rev. 2018, 50, 1-15. [CrossRef]

3. Kaspereit, T.; Lopatta, K. The Value Relevance of SAM's Corporate Sustainability Ranking and GRI Sustainability Reporting in the European Stock Markets. Bus. Ethics Eur. Rev. 2016, 25, 1-24. [CrossRef]

4. Doh, J.P.; Howton, S.D.; Howton, S.W.; Siegel, D.S. Does the Market Respond to an Endorsement of Social Responsibility? the Role of Institutions, Information, and Legitimacy. J. Manag. 2010, 36, 1461-1485. [CrossRef]

5. Hawn, O.; Chatterji, A.K.; Mitchell, W. Do Investors Actually Value Sustainability? New Evidence from Investor Reactions to the Dow Jones Sustainability Index (DJSI). Strateg. Manag. J. 2018, 39, 949-976. [CrossRef] 
6. Kappou, K.; Oikonomou, I. Is there a Gold Social Seal? the Financial Effects of Additions to and Deletions from Social Stock Indices. J. Bus. Ethics 2016, 133, 533-552. [CrossRef]

7. Revelli, C.; Viviani, J. Financial Performance of Socially Responsible Investing (SRI): What have we Learned? A Meta-analysis. Bus. Ethics Eur. Rev. 2015, 24, 158-185. [CrossRef]

8. Chatterji, A.; Levine, D. Breaking Down the Wall of Codes: Evaluating Non-Financial Performance Measurement. Calif. Manag. Rev. 2006, 48, 29-51. [CrossRef]

9. Pagano, M.S.; Sinclair, G.; Yang, T. Understanding ESG ratings and ESG indexes. In Research Handbook of Finance and Sustainability; Boubaker, S., Cumming, D., Nguyen, D.K., Eds.; Cheltenham, UK; pp. 339-371.

10. Ziegler, A.; Schröder, M. What Determines the Inclusion in a Sustainability Stock Index?: A Panel Data Analysis for European Firms. Ecol. Econ. 2010, 69, 848-856. [CrossRef]

11. Searcy, C.; Elkhawas, D. Corporate Sustainability Ratings: An Investigation into how Corporations use the Dow Jones Sustainability Index. J. Clean. Prod. 2012, 35, 79-92. [CrossRef]

12. Christensen, D.M. Corporate Accountability Reporting and High-Profile Misconduct. Account. Rev. 2016, 91, 377-399. [CrossRef]

13. Topping, N. How does sustainability disclosure drive behavior change? J. Appl. Corp. Finan. 2012, 24, 45-48. [CrossRef]

14. Endrikat, J.; Guenther, E.; Hoppe, H. Making Sense of Conflicting Empirical Findings: A Meta-Analytic Review of the Relationship between Corporate Environmental and Financial Performance. Eur. Manag. J. 2014, 32, 735-751. [CrossRef]

15. Ruggiero, P.; Cupertino, S. CSR Strategic Approach, Financial Resources and Corporate Social Performance: The Mediating Effect of Innovation. Sustainability 2018, 10, 3611. [CrossRef]

16. Roig-Tierno, N.; Gonzalez-Cruz, T.F.; Llopis-Martinez, J. An Overview of Qualitative Comparative Analysis: A Bibliometric Analysis. J. Innovat. Knowl. 2017, 2, 15-23. [CrossRef]

17. Isaksson, L.E.; Woodside, A.G. Modeling Firm Heterogeneity in Corporate Social Performance and Financial Performance. J. Bus. Res. 2016, 69, 3285-3314. [CrossRef]

18. Aguinis, H.; Glavas, A. What we Know and Don't Know about Corporate Social Responsibility: A Review and Research Agenda. J. Manag. 2012, 38, 932-968. [CrossRef]

19. Busch, T.; Friede, G. The Robustness of the Corporate Social and Financial Performance Relation: A Second-Order Meta-Analysis. Corp. Soc. Respons. Environ. Manag. 2018, 25, 583-608. [CrossRef]

20. Grewatsch, S.; Kleindienst, I. When does it Pay to be Good? Moderators and Mediators in the Corporate Sustainability-Corporate Financial Performance Relationship: A Critical Review. J. Bus. Ethics 2017, 145, 383-416. [CrossRef]

21. Wang, Q.; Dou, J.; Jia, S. A Meta-Analytic Review of Corporate Social Responsibility and Corporate Financial Performance: The Moderating Effect of Contextual Factors. Bus. Soc. 2016, 55, 1083-1121. [CrossRef]

22. Perrini, F.; Russo, A.; Tencati, A.; Vurro, C. Deconstructing the Relationship between Corporate Social and Financial Performance. J. Bus. Ethics 2011, 102, 59-76. [CrossRef]

23. Humphrey, J.E.; Lee, D.D.; Shen, Y. Does it Cost to be Sustainable? J. Corp. Financ. 2012, 18, 626-639. [CrossRef]

24. Hussain, N.; Rigoni, U.; Cavezzali, E. Does it Pay to be Sustainable? Looking Inside the Black Box of the Relationship between Sustainability Performance and Financial Performance. Corp. Soc. Respons. Environ. Manag. 2018, 25, 1198-1211. [CrossRef]

25. McWilliams, A.; Siegel, D. Corporate Social Responsibility and Financial Performance: Correlation Or Misspecification? Strateg. Manag. J. 2000, 21, 603-609. [CrossRef]

26. Friede, G.; Busch, T.; Bassen, A. ESG and Financial Performance: Aggregated Evidence from More than 2000 Empirical Studies. J. Sust. Financ. Invest. 2015, 5, 210-233. [CrossRef]

27. Brammer, S.; Millington, A. Does it Pay to be Different? an Analysis of the Relationship between Corporate Social and Financial Performance. Strateg. Manag. J. 2008, 29, 1325-1343. [CrossRef]

28. Lenz, I.; Wetzel, H.A.; Hammerschmidt, M. Can Doing Good Lead to Doing Poorly? Firm Value Implications of CSR in the Face of CSI. J. Acad. Mark. Sci. 2017, 45, 677-697. [CrossRef]

29. Price, J.M.; Sun, W. Doing Good and Doing Bad: The Impact of Corporate Social Responsibility and Irresponsibility on Firm Performance. J. Bus. Res. 2017, 80, 82-97. [CrossRef]

30. Surroca, J.; Tribó, J.A.; Waddock, S. Corporate Responsibility and Financial Performance: The Role of Intangible Resources. Strateg. Manag. J. 2010, 31, 463-490. [CrossRef] 
31. Artiach, T.; Lee, D.; Nelson, D.; Walker, J. The Determinants of Corporate Sustainability Performance. Account. Financ. 2010, 50, 31-51. [CrossRef]

32. Braun, B. What Makes Environmental Management Systems Successful? An Empirical Study in the German Manufacturing Sector. In The Integration of Social, Environmental and Economic Performance; Schaltegger, S., Wagner, M., Eds.; Greenleaf Publishing: Sheffield, UK, 2006; pp. 589-614.

33. Elsayed, K.; Paton, D. The Impact of Financial Performance on Environmental Policy: Does Firm Life Cycle Matter? Bus. Strat. Environ. 2009, 18, 397-413. [CrossRef]

34. Scholtens, B. A Note on the Interaction between Corporate Social Responsibility and Financial Performance. Ecol. Econ. 2008, 68, 46-55. [CrossRef]

35. Testa, M.; D'Amato, A. Corporate Environmental Responsibility and Financial Performance: Does Bidirectional Causality Work? Empirical Evidence from the Manufacturing Industry. Soc. Res. J. 2017, 13, 221-234. [CrossRef]

36. Orlitzky, M.; Schmidt, F.L.; Rynes, S.L. Corporate Social and Financial Performance: A Meta-Analysis. Organ. Stud. 2003, 24, 403-441. [CrossRef]

37. Martínez Ferrero, J.; Frías Aceituno, J. Relationship between Sustainable Development and Financial Performance: International Empirical Research. Bus. Strat. Environ. 2015, 24, 20-39. [CrossRef]

38. Waddock, S.A.; Graves, S.B. The Corporate Social Performance-financial Performance Link. Strateg. Manag. J. 1997, 18, 303-319. [CrossRef]

39. Salzmann, O.; Ionescu-somers, A.; Steger, U. The Business Case for Corporate Sustainability: Literature Review and Research Options. Eur. Manag. J. 2005, 23, 27-36. [CrossRef]

40. Schaltegger, S.; Synnestvedt, T. The Link between 'green' and Economic Success: Environmental Management as the Crucial Trigger between Environmental and Economic Performance. J. Environ. Mana. 2002, 65, 339-346.

41. Skouloudis, A.; Avlonitis, G.J.; Malesios, C.; Evangelinos, K. Priorities and Perceptions of Corporate Social Responsibility: Insights from the Perspective of Greek Business Professionals. Manag. Decis. 2015, 53, 375-401. [CrossRef]

42. Peloza, J. The Challenge of Measuring Financial Impacts from Investments in Corporate Social Performance. J. Manag. 2009, 35, 1518-1541. [CrossRef]

43. Galant, A.; Cadez, S. Corporate Social Responsibility and Financial Performance Relationship: A Review of Measurement Approaches. Ec. Res.-Ekonomska Istraživanja 2017, 30, 676-693. [CrossRef]

44. Dobre, E.; Stanila, O.G.; Brad, L. The Influence of Environmental and Social Performance on Financial Performance: Evidence from Romania's Listed Entities. Sustainability 2015, 7, 2513-2553. [CrossRef]

45. Nollet, J.; Filis, G.; Mitrokostas, E. Corporate Social Responsibility and Financial Performance: A Non-Linear and Disaggregated Approach. Econ. Model. 2016, 52, 400-407. [CrossRef]

46. Statman, M.; Glushkov, D. The Wages of Social Responsibility. Financ. Anal. J. 2009, 65, 33-46. [CrossRef]

47. Fortanier, F.; Kolk, A.; Pinkse, J. Harmonization in CSR Reporting. Manag. Int. Rev. 2011, 51, 665. [CrossRef]

48. Evangelinos, K.; Skouloudis, A. European Perspectives on Corporate Non-Financial Disclosure: Evidence from the Southeast. Int. J. Dis. Gover. 2014, 11, 33-53. [CrossRef]

49. Skouloudis, A.; Evangelinos, K.; Kourmousis, F. Assessing Non-Financial Reports According to the Global Reporting Initiative Guidelines: Evidence from Greece. J. Clean. Prod. 2010, 18, 426-438. [CrossRef]

50. Benlemlih, M. Corporate Social Responsibility and Firm Financing Decisions: A Literature Review. J. Multinat. Financ. Manag. 2017, 42, 1-10. [CrossRef]

51. Fatemi, A.; Glaum, M.; Kaiser, S. ESG Performance and Firm Value: The Moderating Role of Disclosure. Glob. Financ. J. 2018, 38, 45-64. [CrossRef]

52. Marimon, F.; Alonso-Almeida, M.d.M.; Rodríguez, M.d.P.; Cortez Alejandro, K.A. The Worldwide Diffusion of the Global Reporting Initiative: What is the Point? J. Clean. Prod. 2012, 33, 132-144. [CrossRef]

53. Churet, C.; Eccled, R.G. Integrated Reporting, Quality of Management, and Financial Performance. J. Appl. Corp. Financ. 2014, 26, 56-64.

54. Beck, C.; Frost, G.; Jones, S. CSR Disclosure and Financial Performance Revisited: A Cross-Country Analysis. Aust. J. Manag. 2018, 43, 517-537. [CrossRef]

55. Chen, L.; Feldmann, A.; Tang, O. The Relationship between Disclosures of Corporate Social Performance and Financial Performance: Evidences from GRI Reports in Manufacturing Industry. Int. J. Prod. Econ. 2015, 170, 445-456. [CrossRef] 
56. Rezaee, Z.; Tuo, L. Are the Quantity and Quality of Sustainability Disclosures Associated with the Innate and Discretionary Earnings Quality? J. Bus. Ethics 2017, 1-24. [CrossRef]

57. Giannarakis, G. Corporate Governance and Financial Characteristic Effects on the Extent of Corporate Social Responsibility Disclosure. Soc. Respons. J. 2014, 10, 569-590. [CrossRef]

58. Crifo, P.; Forget, V.D.; Teyssier, S. The Price of Environmental, Social and Governance Practice Disclosure: An Experiment with Professional Private Equity Investors. J. Corp. Financ. 2015, 30, 168-194. [CrossRef]

59. Fifka, M. Corporate Responsibility Reporting and its Determinants in Comparative Perspective - a Review of the Empirical Literature and a Meta-Analysis. Bus. Strat. Environ. 2013, 22, 1-35. [CrossRef]

60. Stanwick, S.D.; Stanwick, P.A. The Relationship between Environmental Disclosures and Financial Performance: An Empirical Study of US Firms. Eco-Manag. Aud. 2000, 7, 155-164. [CrossRef]

61. Qiu, Y.; Shaukat, A.; Tharyan, R. Environmental and Social Disclosures: Link with Corporate Financial Performance. Brit. Account. Rev. 2016, 48, 102-116. [CrossRef]

62. Goettsche, M.; Steindl, T.; Gietl, S. Do Customers Affect the Value Relevance of Sustainability Reporting? Empirical Evidence on Stakeholder Interdependence. Bus. Strat. Environ. 2016, 25, 149-164. [CrossRef]

63. Martínez Ferrero, J.; Garcia Sanchez, I.; Cuadrado Ballesteros, B. Effect of Financial Reporting Quality on Sustainability Information Disclosure. Corp. Soc. Respons. Environ. Manag. 2015, 22, 45-64. [CrossRef]

64. Melo, T. Slack-resources Hypothesis: A Critical Analysis Under a Multidimensional Approach to Corporate Social Performance. Soc. Respons. J. 2012, 8, 257-269. [CrossRef]

65. Schreck, P.; Raithel, S. Corporate Social Performance, Firm Size, and Organizational Visibility: Distinct and Joint Effects on Voluntary Sustainability Reporting. Bus. Soc. 2018, 57, 742-778. [CrossRef]

66. Clarkson, P.M.; Li, Y.; Richardson, G.D.; Vasvari, F.P. Revisiting the Relation between Environmental Performance and Environmental Disclosure: An Empirical Analysis. Account. Organ. Soc. 2008, 33, $303-327$. [CrossRef]

67. Hummel, K.; Schlick, C. The Relationship between Sustainability Performance and Sustainability Disclosure - Reconciling Voluntary Disclosure Theory and Legitimacy Theory. J. Account. Public Policy 2016, 35, 455-476. [CrossRef]

68. Eom, K.; Nam, G. Effect of Entry into Socially Responsible Investment Index on Cost of Equity and Firm Value. Sustainability 2017, 9, 717. [CrossRef]

69. Schröder, M. Is there a Difference? the Performance Characteristics of SRI Equity Indices. J. Bus. Financ. Account. 2007, 34, 331-348. [CrossRef]

70. Statman, M. Socially Responsible Indexes. J. Portfolio Manag. 2006, 32, 100-109. [CrossRef]

71. Consolandi, C.; Jaiswal-Dale, A.; Poggiani, E.; Vercelli, A. Global Standards and Ethical Stock Indexes: The Case of the Dow Jones Sustainability Stoxx Index. J. Bus. Ethics 2009, 87, 185-197. [CrossRef]

72. Oberndorfer, U.; Schmidt, P.; Wagner, M.; Ziegler, A. Does the Stock Market Value the Inclusion in a Sustainability Stock Index? an Event Study Analysis for German Firms. J. Environ. Econ. Manag. 2013, 66, 497-509. [CrossRef]

73. Russo, A.; Mariani, M. Drawbacks of a Delisting from a Sustainability Index: An Empirical Analysis. Int. J. Bus. Admin. 2013, 4, 29-40. [CrossRef]

74. Cheung, A.W.K. Do Stock Investors Value Corporate Sustainability? Evidence from an Event Study. J. Bus. Ethics 2011, 99, 145-165. [CrossRef]

75. Curran, M.M.; Moran, D. Impact of the FTSE4Good Index on Firm Price: An Event Study. J. Environ. Manag. 2007, 82, 529-537. [CrossRef] [PubMed]

76. Ragin, C.C. The Comparative Method; Moving Beyond Qualitative and Quantitative Strategies; University of California Press: Berkeley and Los Angeles, CA, USA, 1987.

77. Ragin, C.C. Fuzzy-Set Social Science; University of Chicago Press: Chicago, IL, USA, 2000.

78. Ragin, C.C. Set Relations in Social Research: Evaluating their Consistency and Coverage. Polit. Anal. 2006, 14, 291-310. [CrossRef]

79. Ragin, C.C. Redesigning Social Inquiry: Fuzzy Sets and Beyond; University of Chicago Press: Chicago, IL, USA, 2008.

80. Fiss, P.C. A Set-Theoretic Approach to Organizational Configurations. Acad. Manag. Rev. 2007, 32, 1180-1198. [CrossRef]

81. Fiss, P.C. Building Better Causal Theories: A Fuzzy Set Approach to Typologies in Organization Research. Acad. Manag. J. 2011, 54, 393-420. [CrossRef] 
82. Rihoux, B.; Ragin, C.C. Configurational Comparative Methods: Qualitative Comparative Analysis (QCA) and Related Techniques; Sage Publications: Thousand Oaks CA, USA, 2009.

83. Maggetti, M. Promoting Corporate Responsibility in Private Banking: Necessary and Sufficient Conditions for Joining the Wolfsberg Initiative Against Money Laundering. Bus. Soc. 2014, 53, 787-819. [CrossRef]

84. Slager, C.H. SRI indices and responsible corporate behaviour: a study of the FTSE4GOOD index. PhD Thesis, University of Nottingham, Nottingham, UK, 2012.

85. Cuadrado-Ballesteros, B.; Martínez-Ferrero, J.; García-Sánchez, I.M. Board Structure to Enhance Social Responsibility Development: A Qualitative Comparative Analysis of US Companies. Corp. Soc. Respons. Environ. Manag. 2017, 24, 524-542. [CrossRef]

86. Misangyi, V.F.; Greckhamer, T.; Furnari, S.; Fiss, P.C.; Crilly, D.; Aguilera, R. Embracing Causal Complexity: The Emergence of a Neo-Configurational Perspective. J. Manag. 2017, 43, 255-282. [CrossRef]

87. Woodside, A.G. Moving Beyond Multiple Regression Analysis to Algorithms: Calling for Adoption of a Paradigm Shift from Symmetric to Asymmetric Thinking in Data Analysis and Crafting Theory. J. Bus. Res. 2013, 66, 463-472. [CrossRef]

88. Woodside, A.G. Embrace $\bullet$ perform $\bullet$ model: Complexity Theory, Contrarian Case Analysis, and Multiple Realities. J. Bus. Res. 2014, 67, 2495-2503. [CrossRef]

89. Kan, A.K.S.; Adegbite, E.; El Omari, S.; Abdellatif, M. On the use of Qualitative Comparative Analysis in Management. J. Bus. Res. 2016, 69, 1458-1463.

90. Gjølberg, M. The Origin of Corporate Social Responsibility: Global Forces Or National Legacies? Socio-Econ. Rev. 2009, 7, 605-637. [CrossRef]

91. Rothenhoefer, L.M. The Impact of CSR on Corporate Reputation Perceptions of the Public-A Configurational Multi-Time, Multi-Source Perspective. Bus. Ethics Eur. Rev. 2018. [CrossRef]

92. Skarmeas, D.; Leonidou, C.N.; Saridakis, C. Examining the Role of CSR Skepticism using Fuzzy-Set Qualitative Comparative Analysis. J. Bus. Res. 2014, 67, 1796-1805. [CrossRef]

93. Halme, M.; Rintamäki, J.; Knudsen, J.S.; Lankoski, L.; Kuisma, M. When is there a Sustainability Case for CSR? Pathways to Environmental and Social Performance Improvements. Bus. Soc. 2018. [CrossRef]

94. Wang, D.H.; Yu, T.H.; Chiang, C. Exploring the Value Relevance of Corporate Reputation: A Fuzzy-Set Qualitative Comparative Analysis. J. Bus. Res. 2016, 69, 1329-1332. [CrossRef]

95. Paniagua, J.; Rivelles, R.; Sapena, J. Corporate Governance and Financial Performance: The Role of Ownership and Board Structure. J. Bus. Res. 2018, 89, 229-234. [CrossRef]

96. Primc, K.; Čater, T. Environmental Proactivity and Firm Performance: A Fuzzy-Set Analysis. Manag. Decis. 2015, 53, 648-667. [CrossRef]

97. Demirguc-Kunt, A. Stock Markets, Corporate Finance, and Economic Growth. World Bank Econ. Rev. 1996, 10, 223-239. [CrossRef]

98. Lucey, B.M.; Muckley, C. Robust Global Stock Market Interdependencies. Int. Rev. Financ. Anal. 2011, 20, 215-224. [CrossRef]

99. Stolowy, H.; Paugam, L. The Expansion of Non-Financial Reporting: An Exploratory Study. Account. Bus. Res. 2018, 48, 525-548. [CrossRef]

100. Williams, C.A.; Aguilera, R.V. Corporate Social Responsibility in a Comparative Perspective. In The Oxford Handbook of Corporate Social Responsibility; Crane, A., Matten, D., McWilliams, A., Moon, J., Siegel, D.S., Eds.; Oxford University Press: Oxford, UK, 2008; pp. 452-472.

101. Matten, D.; Moon, J. "Implicit" and "Explicit" CSR: A Conceptual Framework for a Comparative Understanding of Corporate Social Responsibility. Acad. Manag. Rev. 2008, 33, 404-424. [CrossRef]

102. S\&P Dow Jones Indices. Equity S\&P 500, 2018. Available online: https://us.spindices.com/indices/equity/ sp-500 (accessed on 20 December 2018).

103. Government \& Accountability Institute. FLASH REPORT: 85\% of S\&P 500 Index®Companies Publish Sustainability Reports in 2017. 2018. Available online: https:/ / www.ga-institute.com/press-releases/article/ flash-report-85-of-sp-500-indexR-companies-publish-sustainability-reports-in-2017.html (accessed on 20 December 2018).

104. Tamimi, N.; Sebastianelli, R. Transparency among S\&P 500 Companies: An Analysis of ESG Disclosure Scores. Manag. Decis. 2017, 55, 1660-1680.

105. López-Cabarcos, Á.M.; Pérez-Pico, M.A.; López-Pérez, L.M. Does Social Network Sentiment Influence S\&P 500 Environmental \& Socially Responsible Index? Sustainability 2019, 11, 320. 
106. González, M.; Alonso-Almeida, M.; Dominguez, D. Mapping Global Sustainability Report Scoring: A Detailed Analysis of Europe and Asia. Qual. Quant. 2018, 52, 1041-1055. [CrossRef]

107. Pineiro-Chousa, J.; Vizcaíno-González, M.; Romero-Castro, N. Recent advances in standardizing the reporting of nonfinancial information. In Organizational Change and Global Standardization: Solutions to Standards and Norms Overwhelming Organizations; Boje, D.M., Ed.; Routledge: New York, NY, USA, 2015; pp. 169-185.

108. Fernandez-Feijoo, B.; Romero, S.; Ruiz, S. Commitment to Corporate Social Responsibility Measured through Global Reporting Initiative Reporting: Factors Affecting the Behavior of Companies. J. Clean. Prod. 2014, 81, 244-254. [CrossRef]

109. Fuzzy-Set/Qualitative Comparative Analysis, version 3. WINDOWS/MAC Program for Crisp and Fuzzy Sets; Department of Sociology, University of California: Irivine, CA, USA, 2017.

110. Schneider, C.Q.; Wagemann, C. Set-Theoretic Methods for the Social Sciences: A Guide to Qualitative Comparative Analysis; Cambridge University Press: Cambridge, UK, 2012.

111. Emmenegger, P.; Schraff, D.; Walter, A. QCA, the Truth Table Analysis and Large-N Survey Data: The Benefits of Calibration and the Importance of Robustness Tests. In Proceedings of the 2nd International QCA Expert Workshop, Zurich, Switzerland, 5-7 November 2014.

(C) 2019 by the authors. Licensee MDPI, Basel, Switzerland. This article is an open access article distributed under the terms and conditions of the Creative Commons Attribution (CC BY) license (http://creativecommons.org/licenses/by/4.0/). 